\title{
Particulate matter concentrations in residences: an intervention study evaluating stand-alone filters and air conditioners
}

\begin{abstract}
This study, a randomized controlled trial, evaluated the effectiveness of free-standing air filters and window air conditioners (ACs) in 126 low-income households of children with asthma. Households were randomized into a control group, a group receiving a free-standing HEPA filter placed in the child's sleeping area, and a group receiving the filter and a window-mounted AC. Indoor air quality (IAQ) was monitored for week-long periods over three to four seasons. High concentrations of particulate matter (PM) and carbon dioxide were frequently seen. When IAQ was monitored, filters reduced PM levels in the child's bedroom by an average of $50 \%$. Filter use varied greatly among households and declined over time, for example, during weeks when pollutants were monitored, filter use was initially high, averaging $84 \pm 27 \%$, but dropped to $63 \pm 33 \%$ in subsequent seasons. In months when households were not visited, use averaged only $34 \pm 30 \%$. Filter effectiveness did not vary in homes with central or room ACs. The study shows that measurements over multiple seasons are needed to characterize air quality and filter performance. The effectiveness of interventions using free-standing air filters depends on occupant behavior, and strategies to ensure filter use should be an integral part of interventions.
\end{abstract}

\author{
S. Batterman ${ }^{1}$, L. Du ${ }^{1,2}$, G. Mentz ${ }^{1}$, \\ B. Mukherjee', E. Parker ${ }^{3}$, \\ C. Godwin', J.-Y. Chin ${ }^{1}$, \\ A. O'Toole ${ }^{1}$, T. Robins', ' Z. Rowe ${ }^{4}$, \\ T. Lewis ${ }^{1,5}$
}

${ }^{1}$ School of Public Health, University of Michigan, Ann Arbor, MI, USA, ${ }^{2}$ School of Environmental Science and Engineering, Donghua University, Shanghai, China, ${ }^{3}$ College of Public Health, University of lowa, lowa City, IA, USA, ${ }^{4}$ Community Action Against Asthma,

Community Partner at Large, Detroit, MI, USA, ${ }^{5}$ School of Medicine, University of Michigan, Ann Arbor, MI, USA

Key words: Air filters; Air conditioner; Air exchange rate; Asthma; Intervention; Particulate matter.

S. Batterman

School of Public Health

University of Michigan

Room 6075 SPH2, 1420 Washington Heights

Ann Arbor, Ml 48109-2029

USA

Tel.: +1-734-763-2417

Fax: +1-734-763-8095

e-mail: stuartb@umich.edu

Received for review 23 September 2011. Accepted for publication 29 November 2011.

\section{Practical Implications}

Environmental tobacco smoke (ETS) increased particulate matter (PM) levels by about $14 \mu \mathrm{g} / \mathrm{m}^{3}$ and was often detected using ETS-specific tracers despite restrictions on smoking in the house as reported on questionnaires administered to caregivers. PM concentrations depended on season, filter usage, relative humidity, air exchange ratios, number of children, outdoor PM levels, sweeping/dusting, and presence of a central air conditioner (AC). Freestanding air filters can be an effective intervention that provides substantial reductions in PM concentrations if the filters are used. However, filter use was variable across the study population and declined over the study duration, and thus strategies are needed to encourage and maintain use of filters. The variability in filter use suggests that exposure misclassification is a potential problem in intervention studies using filters. The installation of a room AC in the bedroom, intended to limit air exchange ratios, along with an air filter, did not lower PM levels more than the filter alone.

\section{Introduction}

The home is generally the most important setting for pollutant exposure for children and other non-occupationally exposed individuals because so much time is spent indoors (averaging $86-87 \%$ of time for the general population and $89-90 \%$ for children (Klepeis et al., 2001), and because indoor pollutant concentrations often greatly exceed outdoor levels (Wallace, 1996). Pollutant concentrations in residences are determined by multiple factors: the strength of indoor emission sources, for example, tobacco smoke and gas 


\section{Batterman et al.}

stoves; outdoor concentrations, for example, suspended soils and traffic exhaust; airflows, for example, air exchange rates (AERs) in the building that introduce, remove, and mix pollutants; particulate- and/or gas-phase filtration, if any; other building characteristics that influence pollutant deposition and lifetime; and the nature of the pollutant, specifically deposition and reaction rates (Abt et al., 2000; Hussein et al., 2005; Macintosh et al., 2008). These factors, and concentrations of airborne pollutants, can be affected by personal behavior (Abt et al., 2000; Eggleston et al., 2005; McCormack et al., 2008); building characteristics (Allen et al., 2003; Crain et al., 2002; Vanderheide et al., 1997; Weisel et al., 2005); cigarette smoking, incense, gas stoves and other indoor combustion sources; weather including outdoor temperature and wind speed (Lai et al., 2006); season (Allen et al., 2003; Keeler et al., 2002; LeBouf et al., 2008; McCormack et al., 2008; Scapellato et al., 2009; Weisel et al., 2005); central air conditioning; diesel vehicles parked nearby (Meng et al., 2009); window opening (McCormack et al., 2008); and location (Crain et al., 2002; Lai et al., 2006; Weisel et al., 2005). Many of these factors are dynamic, and consequently concentrations and exposures vary at diurnal, seasonal, and decadal time scales.

Analyses of the effects of variability are possible in studies using repeated measurements, specifically pollutant measurements obtained across multiple seasons at the same sites. Seasonal variability of PM concentrations, the focus of the present study, has been examined in a number of studies. In the RIOPA study, which used 48-h sampling periods in two seasons between summer 1999 and spring 2001 in non-smokers homes, indoor levels of $\mathrm{PM}_{2.5}(\mathrm{PM}<2.5 \mu \mathrm{m}$ dia $)$ differed significantly by season in Los Angeles, CA, but not in Houston, TX and Elizabeth, NJ (Weisel et al., 2005). Monitoring in three seasons in bedrooms of 150 asthmatic children in Baltimore, MD, did not show seasonal differences in mean $\mathrm{PM}_{2.5}$ concentrations, although coarse fraction particles $\left(\mathrm{PM}_{2.5-10}\right.$, PM between 2.5 and $10 \mu \mathrm{m}$ dia) were significantly lower in summer (McCormack et al., 2009). In slightly over 100 homes in Regina, Saskatchewan, Canada, $\mathbf{P M}_{2.5}$ concentrations were slightly but significantly higher in summer than winter $\left(7.3\right.$ vs. $6.2 \mu \mathrm{g} / \mathrm{m}^{3}$ ) (Heroux et al., 2010). In 44 residences in Seattle, WA, monitored over 2 years in both heating and non-heating seasons, outdoor $\mathrm{PM}_{2.5}$ accounted for a large fraction (average of $79 \pm 17 \%$ ) of indoor PM levels, and seasonal differences were apparent for particle penetration, AER, and particle decay rates (Allen et al., 2003). In 20 homes of children with asthma in Detroit, Michigan, $\mathrm{PM}_{2.5}$ and $\mathrm{PM}_{10}$ levels in both smokers' and nonsmokers' homes varied seasonally (Keeler et al., 2002). In DEARS, a study of 137 non-smoking households in Detroit, MI, that spanned three winter and three summer seasons, both adult personal and indoor $\mathrm{PM}_{2.5}$ levels were lower in one winter; means in other seasons were similar. In four non-smoking households in Boston, MA, monitored for one or two 6-day periods in winter and summer, $\mathrm{PM}_{0.1-0.5}$ (and AERs) varied on both daily and seasonal bases (Abt et al., 2000). In Padova, Italy, personal $\mathrm{PM}_{10}$ measurements collected as six 24-h samples in different seasons among 31 asthmatic subjects (including 10 smokers) exceeded outdoor concentrations and varied seasonally (Scapellato et al., 2009). These and other studies suggest the significance of seasonal changes in residential and personal concentrations of PM.

Indoor PM concentrations can be reduced quite easily and substantially using free-standing filters (Batterman et al., 2005), which are also called room air filters or purifiers. Such filters may provide some improvement in health and symptoms, for example, reduced frequency of asthma symptoms (Crain et al., 2002; Sublett et al., 2010; Xu et al., 2010). Freestanding filters can be used in many situations, and their use may be particularly well suited for susceptible individuals, for example, children with asthma. We previously evaluated free-standing filters equipped with HEPA (high efficiency particulate air) filters placed in both living rooms and bedrooms of homes in Detroit, MI, and compared performance to predictions of simple box-type models. Filters reduced PM levels in nearly all homes, and reductions averaged $69-80 \%$ on days when the filter was used at least $75 \%$ of the time (Batterman et al., 2005; Du et al., 2011). Many of these homes contained smokers. A study evaluating the longterm effectiveness of HEPA filters in Baltimore, MD, using evaluations at baseline, 6 and 12 months following installation found $\mathrm{PM}_{10}$ reductions of up to $39 \%$ as compared to a control group (Eggleston et al., 2005). More sophisticated air cleaning/ventilating units can further improve indoor air quality (IAQ), but expensive building modifications may be required (Xu et al., 2010).

The rooms or space in a building that can be controlled by a free-standing filter depends on its clean air delivery rate (CADR), the volume of the space, mixing, the AER, and the pollutant characteristics. There are several important sources of inconsistencies in the existing performance evaluations of filters. First, variations in the AER, which is rarely measured in filter studies, can cause several effects. As the AER increases, the filter treats a smaller fraction of air, thus lowering its impact; the contribution of outdoor pollutants to indoor levels rises, decreasing indoor concentrations if outdoor levels are lower than levels those indoors (Allen et al., 2003); and indoor emission sources are increasingly diluted, potentially lowering indoor concentrations if outdoor air is cleaner than in indoors (McCormack et al., 2008). The net effect of the AERs thus depends on both indoor and outdoor 
pollutant levels. Fluctuations associated with AERs might be smaller in homes with ACs where windows remained closed. Beyond AERs, there are additional challenges in real-life performance evaluations of air filters. Filter studies have rarely evaluated seasonal effects, which can affect PM concentrations as well as AERs (Breen et al., 2010). Very few studies have measured how filters are used. Finally, most filter studies have been modest in scope, relatively short in duration, and limited by incompletely known or controlled variables, for example, emission sources, and studies measuring both indoor and outdoor pollutant levels are rare.

A few studies have examined the impact of ACs on IAQ. Air conditioning can reduce relative humidity and thus may lower concentrations of dust mites and allergens (Arlian et al., 2001; Delfino et al., 1997; Lintner and Brame, 1993; Munir et al., 1994). Because air conditioning requires closed windows, AERs may be lowered, which can impact pollutant levels, as just described. Finally, central and some room ACs utilize filters, and circulating air will be cleaned, at least to some extent. Thus, ACs have the potential to lower indoor PM concentrations if indoor emission sources are minimized.

\section{Objectives}

This study was a randomized controlled trial. Study objectives included characterizing pollutant exposures in homes of children with asthma living in Detroit, MI, evaluating the effectiveness of HEPA air filters in reducing PM concentrations and determining effects of ACs on PM concentrations and filter performance. Study methods were designed to obtain long-term, representative, and robust results. This research was part of an epidemiological study investigating the effectiveness of air filters for alleviating symptoms of children with asthma in Detroit, MI. This study was conducted as community-based participatory research by the Community Action Against Asthma (CAAA) partnership, which includes community-based organizations, health and human service organizations, and university researchers. Detroit contains about 715,000 people (2010), and the study area is predominantly African American and Latino, household incomes are low, and asthma hospitalization rates are high (Abt et al., 2000; Center for Urban Studies, 2000; Hussein et al., 2005; Macintosh et al., 2008).

\section{Materials and methods}

Recruitment, intervention, and sampling schedule

Households with a child from 6 to 12 years of age identified as having probable persistent asthma were recruited in Detroit, MI, via community-based distri- bution of validated screening questionnaires (Lewis et al., 2004) at schools, health fairs and other community gatherings, and using door-to-door recruitment and contacts of our community partners. Children were classified as having persistent asthma if their parents reported either doctor diagnosis of asthma coupled with routine use of asthma medications or active symptoms, or high frequency or severity of symptoms consistent with asthma. Households were excluded if occupants had participated in one of our previous studies, intended to move in the next 6 months, or if neither English nor Spanish were spoken. Recruitment and study protocols utilized written informed consent and followed ethical guidelines approved by the University of Michigan Institutional Review Board.

The original recruitment protocol required a brief home inspection of all potentially eligible households identified via the screening questionnaire prior to study enrollment to determine whether the child's bedroom window could accommodate a study AC and whether a suitable electrical outlet was nearby. Some funds were available for minor electrical outlet upgrades performed by a licensed electrician when necessary. Owing to logistical issues (e.g., scheduling visits for the home inspections and electrician if needed) and household characteristics (e.g., windows that could not receive the AC), recruitment was extremely slow and many otherwise eligible families were being excluded. With the advice and approval of our data safety monitoring board, the recruitment protocol was modified to allow enrollment prior to home inspection using a two-stage randomization process. In the modified protocol, households were initially randomized to either the 'control' or the filter group. Households in the latter group then underwent the household inspection, followed up with an electrician visit if necessary, and those households capable of receiving an $\mathrm{AC}$ were randomly assigned to receive an $\mathrm{AC}$ or not. If the home could not accept the AC, it was assigned to the 'standard' intervention group that received only the filter. All households received community health worker (CHW) home education visits. The final sample contained 126 households randomized to one of three groups: the control group receiving only $\mathrm{CHW}$ visits $(N=37)$; the 'standard' intervention group receiving a filter and the CHW visits $(N=47)$; and the 'enhanced' intervention group receiving the filter, the $\mathrm{CHW}$ visits, and the room $\operatorname{AC}(N=42)$.

Filters and ACs were provided at no cost and could be kept by the household after the study concluded. These households also received $\$ 10$ for the home inspection; \$15 for each week-long data collection home visit; and $\$ 15$ for electricity consumed by the filter during each visit. Households not receiving filters received $\$ 100$ plus the same incentive for each data collection visit. 


\section{Batterman et al.}

Households entered the study on a rolling basis beginning from March 2009 to February 2010. Field work was concluded in September 2010. On most weeks, 6-10 homes were monitored. This study reports on a total of 346 week-long household visits. Table 1 shows the number of visits by season.

In the middle of the initial week-long 'baseline' visit, both standard and enhanced intervention groups received a stand-alone air filter that was placed in the child's bedroom. The technician and interviewers instructed caregivers on the use of the filter (and AC, if installed, see below). The unit (Whispure 510; Whirlpool Corporation, Benton Harbor, MI, USA) featured a carbon-impregnated pre-filter, a HEPA filter, four fan speed settings, a vertical discharge, and a manufacturer's maximum CADR of $330 \mathrm{CFM}\left(9.36 \mathrm{~m}^{3} / \mathrm{min}\right)$. The manufacturer recommends this unit for rooms up to $500 \mathrm{ft}^{2}\left(46.5 \mathrm{~m}^{2}\right)$ in floor area, which is larger than nearly all of the children's sleep areas (largest was $47.2 \mathrm{~m}^{2}$ ). The pre-filter was porous and light in weight. (We measured the total weight of a new pre-filter as $38 \mathrm{~g}$, but did not determine the quantity of carbon in the pre-filter, though it is unlikely to be more than a few grams.) The pre-filter is expected to have only a minor effect on volatile organic compounds (VOCs) levels, although it did trap dust and larger particles. In previous tests in four homes containing smokers, we measured flow rates from 6.6 (lowest speed) to $12.4 \mathrm{~m}^{3} / \mathrm{min}$ (highest speed) (Batterman et al., 2005). To achieve the best performance, participants were instructed to operate the filter continuously at the highest speed tolerable considering noise and comfort, and to close the door of the bedroom where the filter was placed as much as practical. Participants were instructed how to clean the pre-filter. Our technician replaced prefilters and HEPA filters after 6 months of operation. Filter usage was recorded at $2 \mathrm{~h}$ or shorter intervals. Following the baseline visit, each household received two or three follow-up or 'seasonal' visits spaced approximately three or 4 months apart. (Baseline visits were repeated for the two families that moved prior to their next seasonal visit.)
In May and early June 2010, a technician installed a window-type AC (FAA062P7A; Frigidaire, Augusta, GA, USA) in the child's bedroom in the enhanced intervention group. The manufacturer specified a maximum cooling rate of $6000 \mathrm{BTU} / \mathrm{h}(620$ cooling W/h) and recommends this capacity for rooms up to $216 \mathrm{ft}^{2}$ $\left(20.1 \mathrm{~m}^{2}\right)$. This basic unit had a thermostat and three speeds, but no blend or fresh air vent controls, and we confirmed by inspection and using smoke tubes that no flow path existed between the inside and outside of the unit. Airflow information was unavailable from the manufacturer. In the laboratory, we measured airflows at each speed by configuring an interface from the AC unit's intake and discharge vents to a calibrated flow monitor (Velgrid; Shortridge Instruments, Inc., Scottsdale, AZ, USA), making five measurements on both inflows and outflows separately, and averaging results. The measured airflow rates were 37,40 , and $45 \mathrm{~m}^{3} / \mathrm{min}$ at low, medium, and high settings, respectively.

\section{Walk-through and caregiver surveys}

A technician completed a walk-through inspection in each home to collect information on its characteristics and condition. Using a checklist with direct computer entry, the inspection assessed building characteristics, for example, type of heating and cooling system, evidence of water damage, mold, chipping paint, number of windows, type of covering on floors and furniture, and presence of emission sources such as candles, incense, and room deodorizers. Dimensions of the home and the child's bedroom were measured.

During baseline and seasonal visits, participants completed short surveys that included questions about health status, features of their home, and indoor PMemitting activities, for example, frequency of cigarette smoking, cooking activities, and cleaning practices. After completion of the study, a focus group and survey was completed to identify factors that influenced the household's use of the filters, which will be reported in a subsequent study.

Table 1 Sampling events by season for baseline and seasonal visits

\begin{tabular}{|c|c|c|c|c|c|c|c|c|c|c|}
\hline \multirow[b]{2}{*}{ Season } & \multicolumn{3}{|c|}{ Baseline visits } & \multicolumn{3}{|c|}{ Seasonal visits } & \multicolumn{3}{|c|}{ Total visits } & \multirow[b]{2}{*}{ Total } \\
\hline & Control & Standard & Enhanced & Control & Standard & Enhanced & Control & Standard & Enhanced & \\
\hline 2009 Spring (March-May) & 2 & 4 & 3 & - & - & - & 2 & 4 & 3 & 9 \\
\hline 2009 Summer (June-August) & 14 & 3 & 3 & - & - & - & 13 & 3 & 3 & 19 \\
\hline 2009 Fall (September-November) & 6 & 22 & 15 & 1 & 3 & 4 & 7 & 25 & 19 & 51 \\
\hline 2009 Winter (December-February) & 11 & 18 & 18 & 2 & 1 & 1 & 12 & 19 & 19 & 50 \\
\hline 2010 Spring (March-May) & 4 & - & 3 & 21 & 35 & 32 & 25 & 35 & 35 & 95 \\
\hline 2010 Summer (June-August) & - & - & - & 31 & 45 & 29 & 31 & 45 & 29 & 105 \\
\hline 2010 Fall (September-October) & - & - & - & 4 & 6 & 7 & 4 & 6 & 7 & 17 \\
\hline Total & 37 & 47 & 42 & 59 & 90 & 73 & 94 & 137 & 115 & 346 \\
\hline
\end{tabular}

'Control' = community health worker (CHW) home education visits; 'Standard' = CHW + filter; 'Enhanced' = CHW + filter + air conditioner; 'Total' includes sum of three groups. 
IAQ monitoring

Air quality and ventilation parameters in the child's bedroom and the living area were measured during each week-long assessment. During the baseline sampling week, PM concentrations were measured as seven sequential 24-h samples, sampled at $151 / \mathrm{min}$ using 1- $\mu \mathrm{m}$ 47-mm-dia PTFE filters (225-2749; SKC, Eighty-Four, PA, USA) installed in static-free polypropylene cassettes (Omega Specialty Instruments Co., Houston, TX, USA). The cassette inlets are not sizeselective, and performance is similar to open-face filter sampling. Size-selective inlets were not used for reasons of cost and compatibility with sampling equipment. Seasonal visits used 48-h samples to reduce the number of filters needed. Flows were measured and logged continuously, and flow systems were regularly calibrated using a piston-type flow meter. A blank filter was collected at each house during each sampling week. Filter conditioning and weighing was conducted at $25^{\circ} \mathrm{C}$ and $34 \%$ relative humidity, weights were determined to $1 \mu \mathrm{g}$ using a microbalance (ME-5; Sartorius, Goettingen, Germany), and variation exceeding $3 \mu \mathrm{g}$ in filter weight was flagged and filters reweighed. The estimated limit of quantitation for PM measurements is $3 \mu \mathrm{g} / \mathrm{m}^{3}$. Additional particle measurements included optical particle number counts (PNCs) in $0.3-1.0 \mu \mathrm{m}$ and $1-5 \mu \mathrm{m}$ dia size ranges, measured every 1-min using calibrated instruments (GT-521; MetOne, Grants Pass, OR, USA). The smaller size range is attributable to mostly combustion-related particles, for example, ETS; the larger size includes mechanically generated emissions, for example, floor dust. Side-by-side tests confirmed comparability of PNC measurements, for example, agreement within the 16 instruments deployed was typically within $7 \%$ and $10 \%$ for $0.3-1.0$ and $1-5 \mu \mathrm{m}$ dia size ranges, respectively. Further description of the sampling methods and quality elements is provided elsewhere (Du et al., 2011).

Carbon dioxide $\left(\mathrm{CO}_{2}\right)$ concentrations were measured every $5 \mathrm{~min}$ as a measure of occupancy and ventilation. All 16 IR sensors (C7632A; Honeywell Corp., Morristown, NJ, USA) were calibrated using flow controllers to blend zero air and a certified $\mathrm{CO}_{2}$ gas (1011 ppm; Scott Specialty Gases, Plumstead, PA, USA) at concentrations between 0 and $1011 \mathrm{ppm}$, and rechecked after approximately 6 months, which showed average and maximum variations from standards of $6.5 \%$ and $21 \%$, respectively. Temperature and relative humidity were recorded every 5 min using miniature loggers (Hobo H08; Onset Computer Corporation, Bourne, MA, USA).

VOCs, perfluorocarbon tracers (PFTs) for AER determinations, and ETS tracers were measured using passive samplers (Jia et al., 2007), which were analyzed using thermal desorption, cryofocusing and
GC-MS (Batterman et al., 2002). Duplicate samples were collected in the child's bedroom; a third sample was collected in the living area, along with temperature and humidity. Blanks were taken in each home each week. Target VOCs included 2,5-dimethyl furan and 3-ethenyl pyridine, which are qualitative tracers of ETS (Charles et al., 2008). While low levels of ETS may not always be identified, ETS is nearly certainly present if the tracers were detected. Duplicate VOC and tracer measurements were nearly always within $20 \%$. This study discusses only the ETS and PFT tracers.

AERs in the home and child's sleeping area were estimated using the multizone constant injection method, two different PFTs, and measurements in the bedroom and living room. Two passive emitters of hexafluorobenzene were placed in the living area, and two octafluorotoluene emitters in the sleeping area, typically in opposite corners, each releasing these compounds at a constant rate over the week-long sampling period. Emitters were individually calibrated and checked periodically. AERs for the house and child's sleeping area, and flows between these zones, were determined using PFT concentrations measured at the two locations, the measured volumes of the house and bedroom, and methods presented elsewhere (Batterman et al., 2006).

\section{Data analysis and modeling}

Data processing. Short-term measurements (PNC, $\mathrm{CO}_{2}$, temperature, humidity) were reduced to $1 \mathrm{~h}$ averages, then to 24-hr averages using periods starting at $6 \mathrm{Am}$ to better represent the child's exposure period and to avoid splitting the night into two periods, and finally to weekly averages used in the present analysis. In the baseline week when homes received a filter, $\mathrm{PM}, \mathrm{PNC}$, and $\mathrm{CO}_{2}$ concentrations were determined separately for the 3 or 4 days prior to filter deployment and for the 3 or 4 days following deployment. Duplicate VOC measurements were averaged.

A wide range of variables from the walk-through and caregiver surveys that were plausibly associated with PM levels and/or filter performance were selected for analysis. Additional variables were created to summarize building conditions, for example, total number of locations where deteriorating paint or water damage in the home was noted.

Hourly meteorological data obtained from the Detroit City Airport, located in northeast Detroit, were processed to obtain daily averages of ambient temperature, relative humidity, and wind speed. Table S1 summarizes these data for the study period.

To help account for outdoor PM that can infiltrate into homes, ambient $\mathrm{PM}_{2.5}$ measurements were obtained 


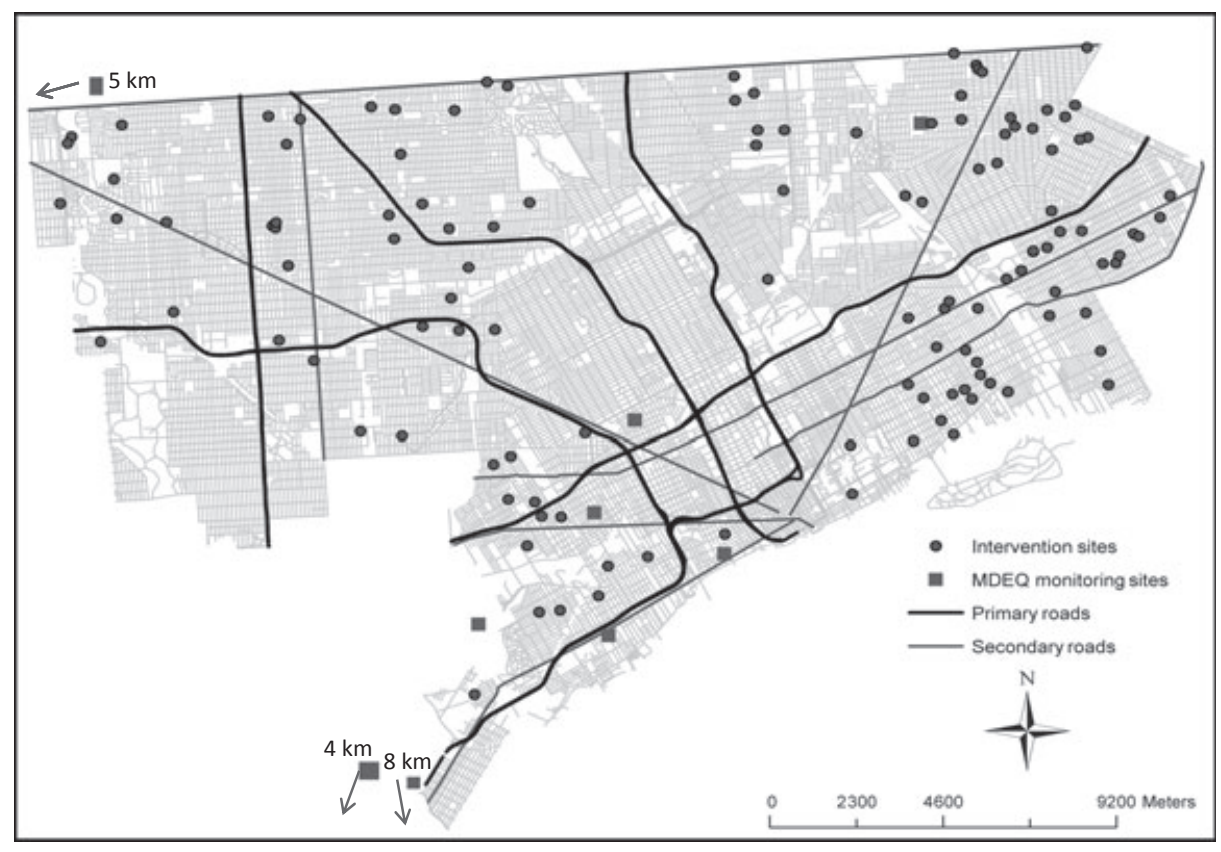

Fig. 1 Map showing location of households, major highways, and secondary streets in Detroit. Also shown are locations of six Detroit $\mathrm{PM}_{2.5}$ monitoring sites; directions and distances to three other sites just outside the city are also indicated. PM, particulate matter

from Detroit area compliance monitoring sites that were representative of population exposure. Daily data were obtained for four sites (Allen Park, Ambassador Bridge, Dearborn, Newberry School) and every third day data from five additional sites (Southwest High School, Linwood, East 7 Mile, Livonia, Wyandotte). The ambient data are summarized in Table S2; Figure 1 shows the location of the monitoring sites in Detroit.

Data analysis. Paired $t$-tests were used to test for differences within the week and for seasonal effects. Seasonal analyses were conducted with summer defined as June, July, and August; fall as September, October, and November; winter as January, February, and March; and spring as April, May, and June. Kruskal-Wallis nonparametric tests were used for differences in medians, and $\mathrm{F}$ and Tukey's tests for means.

Statistical models were used to account for the variation in PM levels among the households and to distinguish and estimate effects of standard and enhanced interventions. Variables potentially associated with indoor PM concentrations were drawn from the walk-through and caregiver surveys, and relevant indoor and outdoor measurements, and tested using ANOVAs and simple regression models. Selected variables were used in general estimating equation (GEE) models, which account for repeated measures (i.e., multiple visits to a home) and control for season, smoking, filter use, intervention group, and other factors. Because indoor and outdoor PM concentrations were positively skewed, values were log-normally transformed in these models. The three models discussed below (and others used in exploratory and sensitivity analyses) were estimated for three outcomes: PM, 0.3-1.0 $\mu \mathrm{m} \mathrm{PNC,} \mathrm{and} \mathrm{1-5} \mu \mathrm{m}$ PNC.

Model 1 included all three randomization groups and evaluated effects of both standard and enhanced interventions:

$$
\begin{aligned}
C_{i, t}= & \beta_{0}+\beta_{1} I_{\text {Enhanced }, i}+\beta_{2} I_{\text {Control }, i} \\
& +\beta_{3} \operatorname{DETS}_{i, t}+\beta_{4} \mathrm{AER}_{\mathrm{LR}, i, t}+\beta_{5} \mathrm{AER}_{\mathrm{BR}, i, t} \\
& +\beta_{6} C_{\mathrm{out}, t}+\beta_{7} T_{i, t}+\beta_{8} \mathrm{RH}_{i, t}+\beta_{9} I_{\mathrm{win}, i, t} \\
& +\beta_{10} I_{\mathrm{spr}, i, t}+\beta_{11} I_{\mathrm{sumn}, i, t}
\end{aligned}
$$

where $C_{\mathrm{i}, \mathrm{t}}=$ concentration in house $i$ and time $t$ (baseline visit or seasonal visit 1, 2 or 3); $I_{\text {Control }, i}$ and $I_{\text {Enhanced }, i}=$ indicator variables for randomization into either the control and enhanced intervention (HEPA filter plus AC) groups, respectively; $\operatorname{DETS}_{i, t}=$ detection of the ETS tracer; $\mathrm{AER}_{\mathrm{LR}, i, t}$ and $\mathrm{AER}_{\mathrm{BR}, i, t}=\mathrm{AERs}$ in living room and bedroom, respectively $(/ \mathrm{h}), \mathrm{C}_{\text {out }, t}=\log$ of outdoor $\mathrm{PM}_{2.5}$ concentration $\left(\mu \mathrm{g} / \mathrm{m}^{3}\right) ; T_{i, t}$ and $\mathrm{RH}_{i, t}=$ average indoor temperature $\left({ }^{\circ} \mathrm{C}\right)$ and relative humidity $(\%)$, respectively; $I_{\mathrm{win}, i, t}, I_{\mathrm{spr}, i, t}$ and $I_{\mathrm{sum}, i, t}=$ indicator variables for winter, spring and summer seasons, respectively; and $\beta_{0}$ through $\beta_{11}=$ estimated parameters. The key parameters are $\beta_{1}$ and $\beta_{2}$, the effect sizes of the standard and enhanced interventions, respectively.

The main goal of model 2 was to evaluate differences between standard and enhanced intervention groups while controlling for filter usage in each 
household, which was measured as the percent of time the filter was used during the IAQ sampling period:

$$
\begin{aligned}
C_{i, t}= & \beta_{0}+\beta_{1} I_{\text {Enhanced }, i}+\beta_{2} \mathrm{Use}_{i, t}+\beta_{3} I_{\text {sum }, i, t} \\
& +\beta_{4} C_{\text {out }, t}+\beta_{5} T_{i, t}+\beta_{6} \mathrm{RH}_{i, t} \\
& +\beta_{7} \mathrm{AER}_{\mathrm{LR}}+\beta_{8} \mathrm{AER}_{\mathrm{BR}} \\
& +\beta_{9} \mathrm{Swept}_{i, t}+\beta_{10} \mathrm{Child}_{i}+\beta_{11} \mathrm{Smoke}_{i} \\
& +\beta_{12} I_{\text {Enhanced }, i} * \mathrm{Use}_{i, t}+\beta_{13} \mathrm{Use}_{i, t} * I_{\text {sum }, i, t} \\
& +\beta_{14} I_{\text {Enhanced }, i} * I_{\text {sum }, i, t}
\end{aligned}
$$

where $\mathrm{Use}_{i, t}=$ fraction of time the filter was used (\%); Swept $_{i, t}=$ indicator variable if the house had been swept or dusted in the last 2 weeks; Child $_{i}=$ number of children in household; Smoke $_{i}=$ number of smokers in the household; and other variables were defined previously. This model contains three interaction terms (discussed in Results), and it excludes observations from the control group, which did not have filters.

To further investigate whether central ACs altered effects of filters and to distinguish effects of the standard and enhanced interventions, a third model was stratified by both the season and the presence of central ACs:

$$
\begin{aligned}
C_{i, t}= & \beta_{0}+\beta_{1} I_{\text {Enhanced }, i}+\beta_{2} I_{\text {Control }, i} \\
& +\beta_{3} \mathrm{DETS}_{i, t}+\beta_{4} C_{\text {out }, t}+\beta_{5} T_{i, t} \\
& +\beta_{6} \mathrm{RH}_{i, t}+\beta_{7} \mathrm{AER}_{\mathrm{LR}, i, t}+\beta_{8} \mathrm{AER}_{\mathrm{BR}, i, t}
\end{aligned}
$$

Like the preceding models, model 3 was estimated for the three outcomes (PM, 0.3-1.0 $\mu \mathrm{m}$ PNC, and 1$5 \mu \mathrm{m}$ PNC) and also for each of the four combinations of the stratifying variables (summer 2010 vs. other seasons, and presence or absence of central ACs). This model has the advantage that interaction terms are not needed (given the two levels of stratification), but the disadvantage that each strata has a small sample size.

Statistical models were run using several data sets, starting with the 'raw' data. Next, missing data was imputed by multiple imputation using IVEWare (SAS for Windows; Survey Research Center, Ann Arbor, MI, USA), which draws missing values from distributions that characterize the conditional relationship of imputed variables to other variables and which accounts for the inter-season correlation of measurements at the same house. Imputations used regression models fitted to the current values of observed and imputed data and an estimated posterior covariance matrix (multivariate normal approximation). We also ran models using a 'partially' imputed data set, which imputed values only if measurements were obtained at that house in that season, for example, imputed data simply completed any measurements that were missing because of an instrumentation problem or other failure. We considered models using the partially imputed data set as the final and most representative, and present results from this data set in this study. To account for potential bias in assignments to the intervention groups, we also estimated models using only those households that 'passed' the home inspection and were eligible for an AC. Differences among the models, which usually were fairly minor, are discussed in the study. The supplemental materials present model estimates using the raw data set. Following Zheng (2000), we computed a marginal $R^{2}$ for each model $\left(R_{\mathrm{m}}^{2}\right)$, which measures the fit of the estimated model in a manner largely analogous to $R_{\mathrm{m}}^{2}$ for regression models.

\section{Results and discussion}

Household characteristics

The study homes were distributed across Detroit (Figure 1). The homes were mostly modest 2- to 4bedroom single-family homes that varied widely in age ( $<9$ to $>100$ years). Most $(88 \%)$ used forced air heating systems, and $30 \%$ had central ACs. Most $(87 \%)$ had some water damage (mostly in basements), and $26 \%$ had visible mold or mildew (most commonly in bathrooms or kitchens). The average occupancy of the homes was $1.7 \pm 0.8$ adults and $2.4 \pm 1.4$ children; the highest was five adults and eight children. Over half $(60 \%)$ of the households included adult smokers, although many households reported limiting indoor smoking by prohibiting it, reducing it, or restricting smoking to one room. Thirty-six percent of the households had dogs or cats. Forty-four percent of the caregivers reported using vacuum cleaners, and all of the child's sleeping areas were reported to have been cleaned in the past 2 weeks by either vacuuming, sweeping, or dusting. Additional characteristics of the homes are listed in Table S3.

Although the numbers of households and visits varied by season and were somewhat unbalanced, group medians of all of the household and occupant characteristics (listed in Table S3) did not vary significantly among control, standard, and intervention groups (Kruskal-Wallis tests, $P<0.05$ ). On this basis, bias was not apparent in the randomization of households to the three groups.

\section{Pollutant levels in residences}

PM levels before filter deployment. Table 2 summarizes $\mathrm{PM}$ and $\mathrm{CO}_{2}$ measurements with and without filters, and Table 3 provides a seasonal breakdown. Concentrations obtained without filters are based on all measurements in the control group (typically an 18day average: 6 days in each baseline and two seasonal visits), and the baseline measurements in the two intervention groups prior to filter deployment (typically a 2-3 day average), with each house weighted 


\section{Batterman et al.}

Table 2 PM, 0.3-1.0 $\mu \mathrm{m}$ PNC, 1-5 $\mu \mathrm{m}$ PNC, and $\mathrm{CO}_{2}$ measurements with and without air filters in baseline and seasonal visits for three groups

\begin{tabular}{|c|c|c|c|c|c|c|c|c|c|c|c|}
\hline \multirow[b]{2}{*}{ Outcome } & \multirow[b]{2}{*}{ Group } & \multicolumn{5}{|c|}{ Without filter use } & \multicolumn{5}{|c|}{ With filter use } \\
\hline & & $n$ & Average & s.d. & Median & $P$-value ${ }^{a}$ & $n$ & Average & s.d. & Median & $P$-value ${ }^{a}$ \\
\hline \multirow[t]{4}{*}{$\mathrm{PM}\left(\mu \mathrm{g} / \mathrm{m}^{3}\right)$} & Control & 35 & 32.5 & 14.7 & 30.4 & 0.003 & & & & & \\
\hline & Standard & 41 & 21.4 & 18.1 & 14.2 & & 46 & 11.8 & 8.8 & 10.0 & 0.015 \\
\hline & Enhanced & 38 & 32.5 & 30.5 & 15.7 & & 37 & 16.8 & 10.9 & 13.8 & \\
\hline & All & 114 & 28.5 & 22.7 & 21.8 & & 83 & 14.1 & 10.1 & 11.4 & \\
\hline \multirow[t]{4}{*}{$0.3-1.0 \mu \mathrm{m}$ PNC (\#/I) } & Control & 35 & 94,757 & 46,653 & 80,498 & $<0.001$ & & & & & \\
\hline & Standard & 40 & 57,857 & 57,981 & 39,120 & & 46 & 30,444 & 25,386 & 20,522 & 0.007 \\
\hline & Enhanced & 38 & 71,501 & 64,364 & 49,985 & & 37 & 43,528 & 27,880 & 37,155 & \\
\hline & All & 113 & 73,875 & 58,564 & 58,101 & & 83 & 36,277 & 27,161 & 27,802 & \\
\hline \multirow[t]{4}{*}{ 1-5 $\mu \mathrm{m}$ PNC (\#/I) } & Control & 35 & 1774 & 1470 & 1306 & $<0.001$ & & & & & \\
\hline & Standard & 40 & 1356 & 1361 & 839 & & 46 & 459 & 403 & 325 & 0.042 \\
\hline & Enhanced & 38 & 1516 & 1470 & 933 & & 37 & 623 & 467 & 542 & \\
\hline & All & 116 & 1298 & 1325 & 846 & & 83 & 532 & 438 & 399 & \\
\hline \multirow[t]{4}{*}{$\mathrm{CO}_{2}(\mathrm{ppm})$} & Control & 35 & 925 & 304 & 843 & 0.022 & & & & & \\
\hline & Standard & 46 & 1183 & 468 & 1011 & & 46 & 966 & 260 & 912 & 0.923 \\
\hline & Enhanced & 40 & 1182 & 501 & 1079 & & 39 & 972 & 287 & 953 & \\
\hline & All & 121 & 1108 & 451 & 969 & & 85 & 969 & 271 & 948 & \\
\hline
\end{tabular}

The $\mathrm{CO}_{2}$ average and $\mathrm{SD}$ may be underestimated (see text).

$\mathrm{PM}=$ particulate matter; $\mathrm{PNC}=$ particle number count.

a $P$-value from Kruskal-Wallis test.

Table 3 PM, 0.3-1.0 $\mu \mathrm{m}$ PNC, 1-5 $\mu \mathrm{m}$ PNC, and $\mathrm{CO}_{2}$ measurements for three groups by season

\begin{tabular}{|c|c|c|c|c|c|c|c|c|c|c|c|c|c|c|c|c|c|c|c|}
\hline \multirow[b]{2}{*}{ Outcome } & \multirow[b]{2}{*}{ Season } & \multicolumn{4}{|c|}{ Control } & \multicolumn{4}{|c|}{ Standard } & \multicolumn{4}{|c|}{ Enhanced } & \multicolumn{4}{|c|}{ All groups } & \multicolumn{2}{|l|}{$R(\%)$} \\
\hline & & $n$ & Average & s.d. & Median & $n$ & Average & s.d. & Median & $n$ & Average & s.d. & Median & $n$ & Average & s.d. & Median & Standard & Enhanced \\
\hline \multirow[t]{6}{*}{$\mathrm{PM}\left(\mu \mathrm{g} / \mathrm{m}^{3}\right)$} & Spring & 26 & 30.7 & 17.7 & 24.7 & 36 & 13.7 & 13.2 & 10.2 & 33 & 17.9 & 15.2 & 14.0 & 95 & 19.8 & 16.6 & 16.4 & 59 & 43 \\
\hline & Summer & 42 & 36.7 & 20.3 & 31.9 & 46 & 12.0 & 9.2 & 9.7 & 31 & 16.5 & 11.9 & 13.1 & 119 & 21.9 & 18.3 & 17.0 & 70 & 59 \\
\hline & Fall & 10 & 27.6 & 12.9 & 27.0 & 22 & 11.7 & 13.6 & 7.5 & 15 & 23.2 & 21.9 & 14.6 & 47 & 18.7 & 17.6 & 15.4 & 72 & 46 \\
\hline & Winter & 12 & 24.0 & 12.9 & 26.9 & 11 & 2.8 & 2.9 & 2.3 & 12 & 8.3 & 11.7 & 5.0 & 35 & 12.0 & 13.6 & 6.1 & 91 & 81 \\
\hline & All & 90 & 32.2 & 18.4 & 28.9 & 115 & 11.6 & 11.4 & 8.8 & 91 & 17.0 & 15.4 & 12.0 & 296 & 19.6 & 17.3 & 14.7 & 69 & 58 \\
\hline & $P$-value ${ }^{a}$ & \multicolumn{4}{|c|}{0.083} & \multicolumn{4}{|c|}{0.001} & \multicolumn{4}{|c|}{0.010} & \multicolumn{4}{|c|}{0.001} & & \\
\hline \multirow{6}{*}{ 0.3-1.0 $\mu \mathrm{m}$ PNC (\#/l) } & Spring & 26 & 80,961 & 47,165 & 69,370 & 36 & 28,563 & 29,224 & 19,566 & 33 & 38,145 & 35,088 & 28,737 & 95 & 46,232 & 42,484 & 34,780 & 72 & 59 \\
\hline & Summer & 39 & 112,422 & 58,390 & 98,683 & 45 & 43,603 & 36,759 & 33,983 & 31 & 57,649 & 36,837 & 58,419 & 115 & 70,728 & 54,284 & 61,323 & 66 & 41 \\
\hline & Fall & 10 & 113,567 & 67,077 & 104,557 & 24 & 18,503 & 20,723 & 11,843 & 15 & 46,138 & 57,823 & 25,741 & 49 & 46,364 & 57,910 & 23,025 & 89 & 75 \\
\hline & Winter & 10 & 40,437 & 21,342 & 32,893 & 13 & 7185 & 9,291 & 3,152 & 15 & 34,537 & 62,899 & 13,563 & 38 & 26,732 & 42,959 & 13,588 & 90 & 59 \\
\hline & All & 85 & 94,464 & 57,727 & 84,037 & 118 & 29,897 & 31,838 & 19,355 & 94 & 45,277 & 45,255 & 33,094 & 297 & 53,244 & 52,107 & 37,479 & 77 & 61 \\
\hline & $P$-value ${ }^{a}$ & \multicolumn{4}{|c|}{$<0.001$} & \multicolumn{4}{|c|}{$<0.001$} & \multicolumn{4}{|c|}{0.007} & \multicolumn{4}{|c|}{$<0.001$} & & \\
\hline \multirow[t]{6}{*}{ 1-5 $\mu \mathrm{m}$ PNC (\#/I) } & Spring & 26 & 2119 & 2362 & 1212 & 36 & 610 & 690 & 362 & 33 & 783 & 791 & 472 & 95 & 1083 & 1512 & 658 & 70 & 61 \\
\hline & Summer & 39 & 1669 & 1739 & 1122 & 45 & 501 & 553 & 273 & 31 & 552 & 444 & 420 & 115 & 911 & 1215 & 565 & 76 & 63 \\
\hline & Fall & 10 & 1703 & 979 & 1325 & 24 & 367 & 410 & 213 & 15 & 862 & 1101 & 453 & 49 & 791 & 937 & 453 & 84 & 66 \\
\hline & Winter & 10 & 1421 & 1122 & 1150 & 13 & 93 & 100 & 52 & 15 & 352 & 468 & 202 & 38 & 545 & 828 & 191 & 95 & 82 \\
\hline & All & 85 & 1781 & 1823 & 1175 & 118 & 462 & 562 & 259 & 94 & 651 & 725 & 405 & 297 & 900 & 1246 & 477 & 78 & 66 \\
\hline & $P$-value ${ }^{a}$ & \multicolumn{4}{|c|}{0.653} & \multicolumn{4}{|c|}{$<0.001$} & \multicolumn{4}{|c|}{0.134} & \multicolumn{4}{|c|}{0.001} & & \\
\hline \multirow[t]{6}{*}{$\mathrm{CO}_{2}(\mathrm{ppm})$} & Spring & 25 & 909 & 297 & 904 & 36 & 971 & 301 & 976 & 33 & 927 & 281 & 846 & 94 & 939 & 291 & 898 & -8 & 6 \\
\hline & Summer & 38 & 921 & 494 & 717 & 46 & 765 & 289 & 695 & 32 & 892 & 396 & 787 & 116 & 851 & 398 & 704 & 3 & -10 \\
\hline & Fall & 10 & 895 & 215 & 858 & 29 & 1232 & 477 & 1043 & 22 & 1056 & 430 & 984 & 61 & 1113 & 440 & 1010 & -22 & -15 \\
\hline & Winter & 11 & 1022 & 464 & 864 & 19 & 1022 & 475 & 828 & 18 & 1066 & 533 & 909 & 48 & 1038 & 485 & 862 & 4 & -5 \\
\hline & All & 84 & 927 & 408 & 791 & 130 & 964 & 407 & 861 & 105 & 967 & 400 & 866 & 319 & 955 & 404 & 846 & -9 & -9 \\
\hline & $P$-value ${ }^{a}$ & \multicolumn{4}{|c|}{0.515} & \multicolumn{4}{|c|}{$<0.001$} & \multicolumn{4}{|c|}{0.298} & & & 0.001 & & & \\
\hline
\end{tabular}

Results for standard and enhanced groups exclude baseline measurements without filter. $\mathrm{CO}_{2}$ average and s.d. may be underestimated (see text).

$\mathrm{PM}=$ particulate matter; $\mathrm{PNC}=$ particle number count; $R=$ reduction in control $(\%$, median concentrations).

${ }^{a} P$-value from Kruskal-Wallis test.

equally. Without filters, PM concentrations across the study homes averaged $29 \pm 23 \mu \mathrm{g} / \mathrm{m}^{3}(N=114)$. Concentrations varied across the three intervention groups $(P<0.01)$, but this was largely attributable to seasonal effects and the unbalanced sample sizes in each season (discussed below). We did not find systematic day-to-day or weekend-weekday differences during the baseline sampling week (Du et al., 2011). 
However, seasonal variation was strong, for example, PM levels fell to $24 \pm 13 \mu \mathrm{g} / \mathrm{m}^{3}$ during the winter in the control group, and proportionately larger changes were seen in $0.3-1 \mu \mathrm{m}$ PNC concentrations (Table 3).

The three PM measures were highly correlated, for example, correlation coefficients between PM and 0.31.0 and $1-5 \mu \mathrm{m}$ PNCs were 0.72 and 0.74 , respectively $(N=279$ and 279$)$, and $0.81(N=297)$ between the two PNC measurements (Pearson $r, \log$ values, weekly averages, all groups). Despite the high correlation, different factors influenced these outcomes, as shown later in statistical modeling.

The PM concentrations are comparable to levels measured in other US cities. In 137 mostly nonsmoking households in the DEARS study in Detroit, MI, $\mathrm{PM}_{2.5}$ and $\mathrm{PM}_{2.5-10}$ (fine and coarse fraction) measured in living rooms averaged $19 \pm 20$ and $13 \pm 19 \mu \mathrm{g} / \mathrm{m}^{3}$, respectively (Williams et al., 2009), thus giving a $\mathrm{PM}_{10}$ average of $33 \mu \mathrm{g} / \mathrm{m}^{3}$, and indoor $\mathrm{PM}_{2.5}$ concentrations were lower in winter than summer by $5 \mu \mathrm{g} / \mathrm{m}^{3}$ (Rodes et al., 2010). In an earlier Detroit study examining 20 homes, $\mathrm{PM}_{2.5}$ concentrations in smokers' homes averaged $34 \pm 11$ and $45 \pm 22 \mu \mathrm{g} / \mathrm{m}^{3}$ in summer and winter, respectively, and $\mathrm{PM}_{10}$ averaged $54 \pm 14 \mu \mathrm{g} / \mathrm{m}^{3}$ and $69 \pm 47 \mu \mathrm{g} /$ $\mathrm{m}^{3}$; in non-smokers' homes, $\mathrm{PM}_{2.5}$ averaged $22 \pm 15$ and $18 \pm 9 \mu \mathrm{g} / \mathrm{m}^{3}$, in summer and winter, respectively, and $\mathrm{PM}_{10}$ averaged $36 \pm 17$ and $30 \pm 14 \mu \mathrm{g} / \mathrm{m}^{3}$ (Keeler et al., 2002). These studies suggest that PM levels decrease in non-smoker's homes in winter, but increase in smoker's homes. In the present study, the lower wintertime levels may result from filters in the forced air heating systems used in most of the study homes, which typically utilize low efficiency filters that remove some PM when the house is heated and air is circulating. The higher levels in smokers' homes in winter may be due to more indoor smoking (because it may be too cold to smoke outdoors) and enhanced distribution of ETS throughout the house because of the operation of the mechanical (forced air) heating system. Some of the effect of these factors may be countered by seasonal changes in AERs, which increased slightly in winter (as described later).

PM levels after filter deployment. After filter deployment, PM concentrations in both standard and enhanced intervention groups were well below levels in the control group. With the filters deployed, concentrations averaged $14 \pm 10 \mu \mathrm{g} / \mathrm{m}^{3} \quad(N=83)$, based on the multiseason household average (typically 2-3 days of the baseline visit and 6 days in each of two seasonal visits; Table 2). On this basis, filters reduced levels by $15 \pm 13 \mu \mathrm{g} / \mathrm{m}^{3}$ or $50 \%$ from pre-intervention levels. Both PNC sizes showed comparable or larger reductions. Thus, filters effectively controlled PM in at least the $0.3-5.0 \mu \mathrm{m}$ size range. We previously reported higher removals for the same filters in an analysis that required filter use to exceed $75 \%$ (Batterman et al., 2005; Du et al., 2011). The assessment in the present study is more representative because no such constraint was imposed.

The seasonal variation seen in baseline measurements without filter use was also seen when filters were deployed (Table 3). PM, 0.3-1.0 PNC, and 1-5 $\mu \mathrm{m}$ PNC concentrations were lowest in winter, sometimes by a large amount; PM and $0.3-1.0 \mu \mathrm{m}$ PNC levels were highest in spring, summer, and fall; and 1-5 $\mu \mathrm{m}$ PNC levels were highest in spring (although only several of the $1-5 \mu \mathrm{m}$ PNC changes were statistically significant). The similarity between PM and $0.3-1.0 \mu \mathrm{m}$ PNC trends suggests that small particles $(<1 \mu \mathrm{m})$ accounted for the majority of PM. Compared to the control group, the standard and enhanced groups had significantly lower PM levels in each season, for example, PM concentrations in the standard intervention group were 59-91\% lower; 0.3-1.0 $\mu \mathrm{m}$ PNC levels were 66-90\% lower, and 1-5 $\mu \mathrm{m}$ PNC levels were 70$95 \%$ lower. Reductions in the enhanced group tended to be smaller: PM concentrations in the standard intervention group were $43-81 \%$ lower; $0.3-1.0 \mu \mathrm{m}$ PNC levels were $41-75 \%$ lower, and $1-5 \mu \mathrm{m}$ PNC levels were $61-82 \%$ lower. These comparisons do not control for differences between groups, for example, filter usage or ETS.

$\mathrm{CO}_{2}$ levels. The median and interquartile range of $\mathrm{CO}_{2}$ levels in the households before filters were deployed were 969 and $593 \mathrm{ppm}$, respectively $(N=121$; Table 2). Median $\mathrm{CO}_{2}$ levels among the three groups differed before but not after filters were installed. $\mathrm{CO}_{2}$ levels tended to be lowest in summer and highest in fall and winter (Table 3). Short-term levels frequently exceeded the instrument's range (about $2100 \mathrm{ppm}$ ), thus the average, standard deviation, and maximum statistics for $\mathrm{CO}_{2}$ in Tables 2 and 3 are underestimated; however, medians are accurate.

$\mathrm{CO}_{2}$ levels exceeding $1000 \mathrm{ppm}$ above the ambient level (about $380 \mathrm{ppm}$ ) indicate low ventilation and/or crowding (ventilation rate $<7 \mathrm{l} / \mathrm{s} /$ occupant) (Morey et al., 2011), which can increase concentrations from building emission sources and indicate excess humidity, a concern for biological contaminants. A total of 38 homes $(30 \%)$ experienced at least 1 week during the study in which the median weekly $\mathrm{CO}_{2}$ level exceeded $1380 \mathrm{ppm}$. The $\mathrm{CO}_{2}$ statistics are based on multiday averaging periods that include times when children (and others) are not at home. Consequently, $\mathrm{CO}_{2}$ levels during occupied periods were considerably higher.

Outdoor PM concentrations. Long-term $\mathrm{PM}_{2.5}$ concentrations measured at the nine ambient monitoring sites were similar $\left(8.4-11.7 \mu \mathrm{g} / \mathrm{m}^{3}\right)$, and the multisite average was $10.0 \pm 1.0 \mu \mathrm{g} / \mathrm{m}^{3}$. Daily $\mathrm{PM}_{2.5}$ levels across these nine sites were highly correlated 


\section{Batterman et al.}

$(0.86<r<0.98)$. Some seasonal variation was seen, for example, concentrations were often highest in winter (MDEQ, 2010), although no consistent patterns were seen over the study period (Table S2). A daily spatial average of outdoor $\mathrm{PM}_{2.5}$ measurements was computed for use in subsequent statistical analyses. Over the study period, the spatial average had a mean concentration of $10.8 \pm 5.6 \mu \mathrm{g} / \mathrm{m}^{3}$, range from 1 to $34 \mu \mathrm{g} / \mathrm{m}^{3}$, and 90th percentile concentration of $18 \mu \mathrm{g} / \mathrm{m}^{3}$.

Ambient $\mathrm{PM}_{2.5}$ levels were weakly correlated with the indoor measurements; for example, considering all groups, the correlation coefficients between ambient $\mathrm{PM}_{2.5}$ and indoor PM, 0.3-1.0 $\mu \mathrm{m}$ and $1-5 \mu \mathrm{m}$ PNC concentrations were $0.12,0.30$, and 0.05 , respectively $(N=279,279$ and $279, \log$ values), and slightly higher, $0.21,0.37$, and $0.07(N=86,85$ and 85) for homes without filters. On a seasonal basis, indoor and outdoor levels did not show similar trends.

Overall, outdoor $\mathrm{PM}_{2.5}$ levels were about one-third of pre-filter indoor levels. However, the outdoor $\mathrm{PM}_{2.5}$ measurements excluded the coarse fraction PM that was included in the indoor measurements. In addition, monitoring at central sites may not be representative of neighborhood levels. Recent studies in Detroit show that spatial gradients are sometimes significant for $\mathrm{PM}_{2.5}$ (Rodes et al., 2010) and more frequently important for coarse fraction PM (PM $\mathrm{PM}_{10-2.5}$; Thornburg et al., 2009) because of the influence of local sources such as industry and highways. Residence- or neighborhood-specific ambient PM measurements would provide more information, but such measurements were unavailable, and we could not validate alternate measures, for example, use of the nearest monitor. Because the nine sites in Detroit showed close agreement, however, the spatial average should provide a useful and generally representative estimate of $\mathrm{PM}_{2.5}$ levels.

\section{Air exchange rates}

AERs in the homes averaged $0.73 \pm 0.76 / \mathrm{h}$ (median $=0.57 / \mathrm{h}, \quad N=263)$ and varied seasonally $(P=0.002)$, for example, AERs were highest in winter $(0.88 \pm 0.63$, median $=0.74)$ and lowest in spring $(0.57 \pm 0.55$, median $=0.40)$. AERs in the bedrooms, which include exchange to other spaces in the house, averaged $1.66 \pm 1.50 / \mathrm{h}($ median $=1.23 / \mathrm{h}, N=253)$ and also varied seasonally $(P=0.049)$. Median AERs in both homes and bedrooms did not differ among the randomization groups throughout the study or in summer 2010 when the enhanced intervention group received a room AC. For a given building, the AER is largely driven by the indoor-outdoor temperature gradient and wind speed (Breen et al., 2010). Thus, owing to both the higher temperature gradient and faster wind speed (Table S1), higher AERs are expected in winter. The higher AERs coupled with the slightly higher levels of outdoor PM in winter (Table S2) might be expected to increase indoor PM levels. However, AERs generally were not significantly associated with indoor PM levels. As discussed later in 'Statistical models', this may result from confounding with other factors, for example, PM removal by furnace filters used in the winter, the relatively modest variation in outdoor PM levels and AERs, and the limitations of the AER measurement, including the time averaged results provided and the assumption that each zone is fully mixed (Batterman et al., 2006). Across all seasons, homes with a central AC (as compared to a room AC just discussed) had lower AERs compared to other homes, for example, averages and medians changed by about $10-20 \%$. These differences were statistically significant for the whole house AER $(P=0.012)$ but not the bedroom AER $(P=0.62)$. Effects were largest in summer when homes with a central AC had both lower and more consistent AERs $(0.50 \pm 0.38, \quad$ median $=0.38$, $N=24)$ compared to other homes $(0.98 \pm 1.44$, median $=0.68, N=36 ; P=0.030$, Mann-Whitney test). The differences in non-summer seasons suggest that homes with central air conditioning may be tighter, for example, better weatherized. Central air conditioning also increased bedroom AERs by 10 $20 \%$, possibly reflecting air circulation through the heating, ventilation and air conditioning (HVAC) system, although these changes were not significant.

Contrary to expectations, providing room ACs to the enhanced intervention group did not significantly alter AERs in either the house or the bedroom, that is, there continued to be no statistical difference between the three groups. However, the enhanced intervention group tended to have slightly lower house AERs and sometimes much lower bedroom AERs. This suggests that the room ACs did not significantly affect house AERs and that bedroom AERs may have been slightly lowered using the room AC in conjunction with a (at least partially) closed bedroom door, as occupants were instructed. Again, these changes were not statistically significant.

\section{Filter use}

Filter use across the study population, depicted in Figure 2, shows several patterns. First, use varied widely among participants, from $0 \%$ to $100 \%$, over the five periods reported (Table S4 provides more details). Second, on average, filter use was high (average use $=70 \pm 33 \%, N=228$ ) during the baseline (latter half) and seasonal visits (week-long periods during which staff repeatedly visited households to conduct monitoring and interviews). Still, use dropped from the first (baseline) visit $(83 \pm 27 \%, N=73)$ to subsequent seasonal visits (first season visit, $63 \pm 34 \%$, 


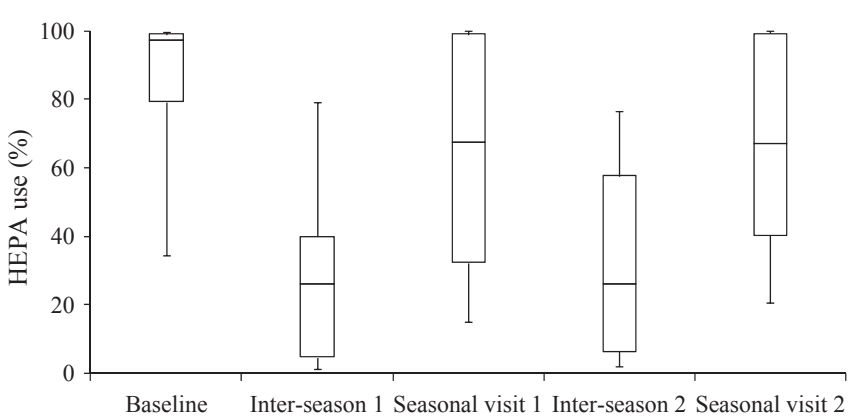

Fig. 2 Filter use over study, showing week-long baseline and seasonal visits, and multi-month long 'inter-season visit' periods. Figure shows median, interquartile, and 10th and 90th percentile use for each period. Total sample size $=358$. Third seasonal visit not shown

$N=79$; second seasonal visit, $64 \pm 31 \%, N=69$; third seasonal visit, $46 \pm 35 \%, N=7)$. Use during the first two seasonal visits did not vary $(P=0.70$, Mann-Whitney test.) Third, in the several months between the baseline and seasonal visits, and between seasonal visits, use dropped to $34 \pm 30 \%(N=143)$, roughly half that during weeks when IAQ monitoring took place. Finally, filter use in the standard intervention group $(75 \pm 30 \%, N=126)$ was slightly but statistically higher than that in the enhanced group $(63 \pm 34 \%, \quad N=102 ; \quad P=0.01, \quad$ Mann-Whitney test.) The key results are that filter use varied greatly among individual households and declined over time. While participants were blinded to the filter use measurements, they were informed about the operation and potential benefits of the filters for their asthmatic child, the filter was provided for free, and the costs of its electricity consumption was reimbursed.

Patterns of filter use have not been previously reported. In designing this study, we had considered the filter intervention to be largely passive in nature, requiring essentially no action by the caregiver, that is, the filter would simply be left on continuously. The initially high use may reflect a 'novelty' effect when the filter was first introduced to the participants. The higher usage during seasonal visits when our staff were present might represent a 'good behavior' effect, reflecting participants' understanding that filters were to be used as much as possible, and also a 'Hawthorne' effect in which our observations altered individual behaviors. The low use during the long periods between IAQ monitoring may also reflect an 'economic' perception that filter use significantly increased the household's electricity consumption, although this cost was reimbursed. Clearly, knowledge of such trends and the factors influencing behavior are critically important for 'active' interventions that depend on participant compliance. The use data acquired in the present study will be addressed in future analyses, but the patterns in study households suggest that exposure and epidemiological studies that use air filter interventions and that do not account for filter use will be biased toward the null. Our findings regarding filter use may apply primarily to intervention studies in which participants are actively recruited and enrolled. Filter use may be higher and more consistent when a family seeks out and purchases a filter unit, a situation in which both greater knowledge of PM's effect on health and motivation to use the filter are expected.

\section{Environmental tobacco smoke}

ETS tracers were detected in a total of 34 homes, most commonly in both the living room and the bedroom. Both tracers and positive survey responses for smoking were found for 19 homes, but tracers were found in an additional 15 homes where smoking was not reported by respondents. Additionally, smoking was reported in 19 homes where tracers were not detected. Thus, the concordance (inter-method agreement) of these methods is not particularly high. Because the ETS tracer measurements were week-long measurements, they do not indicate the temporal pattern of smoking or if the child was present. The discord between ETS detections and survey responses suggests that many respondents understood the significance of smoking but could not control smoking use in the home. In eight homes, levels of the tracer were sometimes higher in the child's bedroom than in the living room, suggesting that smoking took place in the bedroom.

Table 4 shows $\mathrm{PM}$ and $\mathrm{CO}_{2}$ concentrations stratified by the detection of the ETS tracer. Across the three randomization groups and prior to filter deployment, ETS tracer detection was associated with an increase of $12 \pm 35 \mu \mathrm{g} / \mathrm{m}^{3}$ in PM concentrations and significant changes in PNC levels. Still larger increases were associated with ETS in standard and enhanced intervention groups. (In a few cases, PNCs may have been underestimated because of coincident errors, which occurs at about 600,000 \# per 1 for the instrument used.) The estimated ETS contribution was smaller when analyses were based on survey data, a result of misclassification (Du et al., 2011). With filter use, concentrations fell by about half, and ETS detection was associated with a $13 \pm 22 \mu \mathrm{g} / \mathrm{m}^{3}$ increase in PM, nearly the same as just noted, although PNC increments were reduced. A seasonal analysis shows similar trends (Table S6). Thus, filters reduced PM concentrations in smokers' and non-smokers' homes alike; however, the ETS contribution to PM exposures remained about the same. This may occur because of the episodic nature of ETS, which greatly but briefly elevates PM concentrations whether or not the filter is present.

ETS is a well-known contributor to indoor PM. As examples, in three large studies ( $>150$ homes), ETS contributed from 12 to $45 \mu \mathrm{g} / \mathrm{m}^{3}$, depending on the 
Table 4 Particle concentrations stratified by detection of environmental tobacco smoke (ETS) tracers

\begin{tabular}{|c|c|c|c|c|c|c|c|c|}
\hline \multirow[b]{2}{*}{ Outcome } & \multicolumn{3}{|c|}{ No ETS tracer } & \multicolumn{3}{|c|}{ With ETS tracer } & \multicolumn{2}{|c|}{ Difference } \\
\hline & $n$ & Average & s.d. & $n$ & Average & s.d. & Average & s.d. \\
\hline \multicolumn{9}{|c|}{ Without filter use (Control, Standard and Enhanced groups) } \\
\hline $\mathrm{PM}\left(\mu \mathrm{g} / \mathrm{m}^{3}\right)$ & 128 & 26.6 & 17.9 & 41 & 39.0 & 29.8 & 12.4 & 34.8 \\
\hline 0.3-1.0 $\mu \mathrm{m}$ PNC (\#/I) & 124 & 61,987 & 41,911 & 39 & 137,806 & 75,714 & 75,820 & 86,540 \\
\hline $1-5 \mu \mathrm{m}$ PNC (\#/I) & 124 & 1412 & 1328 & 39 & 2262 & 2285 & 850 & 2643 \\
\hline $\mathrm{CO}_{2}(\mathrm{ppm})$ & 131 & 1045 & 465 & 39 & 1093 & 461 & 47 & 655 \\
\hline \multicolumn{9}{|c|}{ Without filter use (Standard and Enhanced groups) } \\
\hline $\mathrm{PM}\left(\mu \mathrm{g} / \mathrm{m}^{3}\right)$ & 62 & 21.6 & 20.6 & 18 & 42.8 & 32.9 & 21.1 & 38.8 \\
\hline 0.3-1.0 $\mu \mathrm{m}$ PNC (\#/I) & 61 & 44,734 & 33,950 & 17 & 135,444 & 82,714 & 90,710 & 89,410 \\
\hline $1-5 \mu \mathrm{m}$ PNC (\#/l) & 61 & 1240 & 1285 & 17 & 2131 & 1639 & 891 & 2083 \\
\hline $\mathrm{CO}_{2}(\mathrm{ppm})$ & 68 & 1161 & 466 & 18 & 1264 & 539 & 103 & 712 \\
\hline \multicolumn{9}{|c|}{ With filter use (Standard and Enhanced groups) } \\
\hline $\mathrm{PM}\left(\mu \mathrm{g} / \mathrm{m}^{3}\right)$ & 172 & 11.7 & 11.1 & 35 & 25.1 & 18.5 & 13.4 & 21.6 \\
\hline 0.3-1.0 $\mu \mathrm{m}$ PNC (\#/I) & 176 & 28,603 & 26,278 & 37 & 74,319 & 61,924 & 45,716 & 67,269 \\
\hline 1-5 $\mu \mathrm{m}$ PNC (\#/I) & 176 & 472 & 569 & 37 & 884 & 851 & 412 & 1024 \\
\hline $\mathrm{CO}_{2}(\mathrm{ppm})$ & 196 & 943 & 405 & 40 & 1052 & 409 & 109 & 575 \\
\hline
\end{tabular}

$\mathrm{PM}=$ particulate matter; $\mathrm{PNC}=$ particle number count.

numbers of smokers and cigarettes smoked (Wallace, 1996); in five RIOPA study homes where ETS was reported, the median $\mathrm{PM}_{2.5}$ concentration increased by $9 \mu \mathrm{g} / \mathrm{m}^{3}$ compared to non-smoking homes (Meng et al., 2009); indoor $\mathrm{PM}_{2.5}$ levels measured in the EXPOLIS study increased from 10 to $48 \mu \mathrm{g} / \mathrm{m}^{3}$ depending on the number of smokers present and based on a model that controlled for several covariates (Lai et al., 2006); and smoking elevated $\mathrm{PM}_{2.5}$ concentrations by $33 \mu \mathrm{g} / \mathrm{m}^{3}$ in inner city Baltimore homes (Breysse et al., 2005). Because most ETS is less than $2 \mu \mathrm{m}$ in dia (Nazaroff et al., 1993), larger changes in the $0.3-1 \mu \mathrm{m}$ PNC were expected. In the present study, ETS increases were somewhat smaller than seen in other studies, probably because air sampling was conducted in the child's bedroom while most smoking likely occurred elsewhere in the residence, and because caregivers were aware of the need to limit ETS exposure to their asthmatic child. Still, PM levels in bedrooms were notably elevated when the ETS tracer was detected.

\section{Statistical models of intervention effectiveness}

A number of house characteristics, occupancy variables, and meteorological variables were associated with indoor PM levels (Table S5). Significant parameters in model 1 for the three PM outcomes included intervention type, ETS detection, outdoor PM levels, temperature, relative humidity, and spring and summer seasons (Table 5). The outdoor $\mathrm{PM}_{2.5}$ concentration was a significant predictor for PM and nearly significant for $0.3-1.0 \mu \mathrm{m}$ PNC. Effects of standard and enhanced interventions, referenced to the control group and averaged across seasons and households, can be estimated as a percentage change in concentrations as $100 \%\left[1-\exp \left(-\beta_{1}\right)\right]$ and $100 \%$ $\left[1-\exp \left(-\beta_{1}+\beta_{2}\right)\right]$, respectively. The standard intervention reduced PM, 0.3-1.0 $\mu \mathrm{m}$ PNC, and 1-5 $\mu \mathrm{m}$ PNC concentrations by $56 \%, 62 \%$ and $67 \%$, respectively, while the enhanced intervention group attained smaller reductions of $41 \%, 45 \%$ and $54 \%$, respectively. While they have similar magnitudes, these reductions are more consistent than estimates based on (uncontrolled) stratified analyses (Tables 2 and 3). Using model 1 with the estimated coefficients and parameter averages, ETS detection was associated with an increase of $8.8 \mu \mathrm{g} / \mathrm{m}^{3}$ in PM in the control homes, smaller than the $14.4 \mu \mathrm{g} / \mathrm{m}^{3}$ estimated from the raw (unimputed) data (Table 2). The effect sizes attributed to the interventions, smoking, and other variables decreased when the imputed data were used, for example, using the raw data, the magnitudes of the coefficients were larger (Table S7), and the effect of cigarette smoking was exactly matched. A second effect of imputation was to reduce the effect of seasonal variability, which can be particularly sensitive to sample size in the present data set; this along with the reduced size of confidence intervals is the major benefit of imputation in the present application. Overall, models using raw and imputed data were very similar, and generally the same variables were significant and influential.

Table 6 shows results for model 2, which incorporated additional covariates and interactions, and which used data from only the standard and enhanced interventions. Significant variables for most outcomes were filter use, ambient $\mathrm{PM}_{2.5}$ concentration, and number of smokers in the household. Filter use was a strong predictor, and parameter $\beta_{2}$ (which multiplies filter use in percent) is a key result. Based on the estimated coefficients, the (theoretical) reduction achieved with $100 \%$ filter use is 56,60 , and $61 \%$ for $\mathrm{PM}, 0.3-1.0 \mu \mathrm{m}$ PNC, and $1-5 \mu \mathrm{m}$ PNC, respectively 
Table 5 General estimating equation estimates for model 1 for PM, 0.3-1.0 $\mu \mathrm{m}$ PNC, and 1-5 $\mu \mathrm{m}$ PNC

\begin{tabular}{|c|c|c|c|c|c|c|}
\hline \multirow[b]{2}{*}{ Variable } & \multicolumn{2}{|l|}{$\log P M$} & \multicolumn{2}{|c|}{$\log 0.3-1.0 \mu \mathrm{m}$ PNC } & \multicolumn{2}{|c|}{$\log 1-5 \mu \mathrm{m}$ PNC } \\
\hline & Est. & s.e. & Est. & s.e. & Est. & s.e. \\
\hline Intercept & 0.912 & 0.433 & 7.595 & 0.522 & 5.746 & 0.587 \\
\hline IEnhanced $_{\text {E }}$ & 0.291 & 0.108 & 0.368 & 0.138 & 0.322 & 0.161 \\
\hline IControl & 0.826 & 0.098 & 0.960 & 0.121 & 1.106 & 0.150 \\
\hline DETS & 0.433 & 0.106 & 0.854 & 0.118 & 0.458 & 0.144 \\
\hline$A E R_{L R}$ & 0.099 & 0.058 & 0.046 & 0.061 & 0.040 & 0.085 \\
\hline $\mathrm{AER}_{\mathrm{BR}}$ & 0.034 & 0.026 & 0.047 & 0.025 & 0.029 & 0.035 \\
\hline $\ln ($ Count) & 0.247 & 0.110 & 0.216 & 0.130 & 0.150 & 0.129 \\
\hline $\mathrm{T}$ & 0.014 & 0.012 & 0.045 & 0.017 & -0.012 & 0.017 \\
\hline $\mathrm{RH}$ & 0.013 & 0.004 & 0.016 & 0.005 & 0.008 & 0.006 \\
\hline Winter & -0.089 & 0.153 & 0.092 & 0.166 & -0.322 & 0.212 \\
\hline$I_{\text {Spr }}$ & -0.123 & 0.127 & -0.125 & 0.131 & -0.328 & 0.152 \\
\hline Sum & -0.316 & 0.114 & 0.030 & 0.150 & -0.601 & 0.149 \\
\hline Sample size & \multirow{2}{*}{\multicolumn{2}{|c|}{$\begin{array}{c}378 \\
0.264\end{array}$}} & \multirow{2}{*}{\multicolumn{2}{|c|}{$\begin{array}{c}378 \\
0326\end{array}$}} & \multicolumn{2}{|c|}{$\begin{array}{c}378 \\
0.172\end{array}$} \\
\hline$R_{\mathrm{m}}^{2}$ & & & & & & \\
\hline
\end{tabular}

Bolded values are significant at $\alpha=0.05$.

$\mathrm{AER}=$ air exchange rates; $\mathrm{PM}=$ particulate matter; $\mathrm{PNC}=$ particle number count.

Table 6 General estimating equation estimates for model 2 for PM, 0.3-1.0 $\mu \mathrm{m} \mathrm{PNC,} \mathrm{and} \mathrm{1-5} \mu \mathrm{m}$ PNC

\begin{tabular}{|c|c|c|c|c|c|c|}
\hline \multirow[b]{2}{*}{ Variable } & \multicolumn{2}{|l|}{$\log P M$} & \multicolumn{2}{|c|}{$\log 0.3-1.0 \mu \mathrm{m}$ PNC } & \multicolumn{2}{|c|}{$\log 1-5 \mu \mathrm{m}$ PNC } \\
\hline & Est. & s.e. & Est. & s.e. & Est. & s.e. \\
\hline Intercept & 0.830 & 0.522 & 8.178 & 0.591 & 5.501 & 0.683 \\
\hline$I_{\text {Enhanced }}$ & 0.063 & 0.214 & 0.205 & 0.311 & 0.456 & 0.326 \\
\hline Use & -0.008 & 0.002 & -0.009 & 0.003 & -0.010 & 0.003 \\
\hline ISum & -0.256 & 0.182 & 0.426 & 0.244 & -0.654 & 0.274 \\
\hline $\log C_{\text {out }}$ & 0.379 & 0.134 & 0.371 & 0.150 & 0.336 & 0.152 \\
\hline$T$ & 0.022 & 0.017 & 0.038 & 0.021 & -0.013 & 0.023 \\
\hline $\mathrm{RH}$ & 0.011 & 0.004 & 0.003 & 0.005 & 0.004 & 0.006 \\
\hline $\mathrm{AER}_{\mathrm{LR}}$ & 0.123 & 0.094 & 0.082 & 0.108 & 0.121 & 0.131 \\
\hline $\mathrm{AER}_{\mathrm{BR}}$ & 0.046 & 0.032 & 0.049 & 0.032 & 0.035 & 0.044 \\
\hline Swept & 0.020 & 0.041 & 0.073 & 0.050 & 0.062 & 0.058 \\
\hline Child & 0.057 & 0.050 & -0.010 & 0.057 & 0.030 & 0.073 \\
\hline Smoke & 0.116 & 0.053 & 0.336 & 0.057 & 0.223 & 0.071 \\
\hline$I_{\text {Enhanced }} \times$ Use & 0.003 & 0.002 & 0.002 & 0.004 & -0.003 & 0.004 \\
\hline Use $\times I_{\text {sum }}$ & -0.003 & 0.002 & -0.004 & 0.003 & 0.004 & 0.003 \\
\hline$I_{\text {Enhanced }} \times I_{\text {sum }}$ & -0.096 & 0.139 & -0.084 & 0.222 & -0.050 & 0.225 \\
\hline Sample size & \multirow{2}{*}{\multicolumn{2}{|c|}{$\begin{array}{c}273 \\
0.225\end{array}$}} & \multirow{2}{*}{\multicolumn{2}{|c|}{$\begin{array}{c}273 \\
0.306\end{array}$}} & \multirow{2}{*}{\multicolumn{2}{|c|}{$\begin{array}{c}273 \\
0.171\end{array}$}} \\
\hline$R_{\mathrm{m}}^{2}$ & & & & & & \\
\hline
\end{tabular}

Bolded values are significant at $\alpha=0.05$.

$\mathrm{AER}=$ air exchange rates; $\mathrm{PM}=$ particulate matter; $\mathrm{PNC}=$ particle number count.

(calculated as $100 \%\left\{1-\exp \left[\beta_{2} 100\right]\right\}$ ). The second key result of model 2 is that all coefficients involving $I_{\text {Enhanced, including the interaction terms, were not }}$ significant, indicating that standard and enhanced interventions did not differ. Rather, the positive although not statistically significant coefficients on $I_{\text {Enhanced }}$ and $I_{\text {Enhanced }} \times$ Use terms again suggest lower removals by filters when an AC was present. Model 2 also shows that outdoor $\mathrm{PM}_{2.5}$ concentrations and indoor smoking were significant predictors of the three PM measures. Results were very similar in models using the 'raw' data (without imputations; Table S8), although effect sizes were stronger, as noted above. In addition, these models show that ambient $\mathrm{PM}_{2.5}$ did not affect 1-5 $\mu \mathrm{m}$ PNC measurements; the number of children were significant predictors of the three PM outcomes; and sweeping/dusting tended to increase 1-5 $\mu \mathrm{m}$ PNC measurements (but with marginal statistical significance). Sweeping/dusting and children represent local emission 'sources', for example, children's activity can entrain dust, primarily coarse fraction PM.

Model 3 was designed to identify effects caused by (existing) central and room ACs. A key goal in reviewing results, shown in Table 7 , was to determine whether $\beta_{1}$ was significant, which would indicate that the enhanced intervention improved air quality over the standard intervention, presumably due to the room AC. In summer with homes without central air conditioning, when the room $\mathrm{AC}$ was installed and potentially operating, $\beta_{1}$ was positive for the three 
Table 7 General estimating equation estimates for model 3 for PM, 0.3-1.0 $\mu \mathrm{m}$ PNC, and 1-5 $\mu \mathrm{m}$ PNC showing models stratified by summer 2010 and by central air conditioning

\begin{tabular}{|c|c|c|c|c|c|c|c|c|c|c|c|c|}
\hline \multirow[b]{3}{*}{ Variable } & \multicolumn{6}{|c|}{ All seasons except summer 2010} & \multicolumn{6}{|c|}{ Summer 2010} \\
\hline & \multicolumn{2}{|l|}{$\log P M$} & \multicolumn{2}{|c|}{$\log 0.3-1.0 \mu \mathrm{m}$ PNC } & \multicolumn{2}{|c|}{$\log 1-5 \mu \mathrm{m}$ PNC } & \multicolumn{2}{|l|}{$\log P M$} & \multicolumn{2}{|c|}{$\log 0.3-1.0 \mu \mathrm{m}$ PNC } & \multicolumn{2}{|c|}{$\log 1-5 \mu \mathrm{m}$ PNC } \\
\hline & Est. & s.e. & Est. & s.e. & Est. & s.e. & Est. & s.e. & Est. & s.e. & Est. & s.e. \\
\hline \multicolumn{13}{|c|}{ With central air conditioning } \\
\hline Intercept & 1.486 & 0.932 & 8.891 & 0.929 & 5.392 & 1.719 & -1.245 & 1.728 & 8.327 & 3.524 & 6.390 & 2.194 \\
\hline Enhanced & -0.155 & 0.229 & -0.198 & 0.267 & -0.398 & 0.352 & 0.479 & 0.184 & 0.153 & 0.219 & 0.704 & 0.253 \\
\hline I Control & 0.507 & 0.220 & 0.711 & 0.253 & 0.860 & 0.357 & 1.101 & 0.269 & 0.762 & 0.319 & 1.423 & 0.281 \\
\hline DETS & 0.836 & 0.227 & 1.177 & 0.253 & 0.857 & 0.317 & 0.567 & 0.264 & 1.268 & 0.265 & 1.013 & 0.299 \\
\hline $\log C_{\text {out }}$ & 0.104 & 0.378 & 0.422 & 0.216 & 0.369 & 0.501 & 0.325 & 0.348 & -0.007 & 0.328 & -0.371 & 0.412 \\
\hline$T$ & -0.017 & 0.031 & -0.058 & 0.039 & -0.066 & 0.045 & 0.035 & 0.039 & -0.013 & 0.063 & -0.071 & 0.048 \\
\hline $\mathrm{RH}$ & 0.017 & 0.008 & 0.020 & 0.007 & 0.018 & 0.009 & 0.028 & 0.014 & 0.036 & 0.034 & 0.020 & 0.022 \\
\hline$A E R_{L R}$ & 0.432 & 0.139 & 0.323 & 0.199 & 0.324 & 0.326 & 0.308 & 0.209 & 0.349 & 0.240 & 0.426 & 0.234 \\
\hline $\mathrm{AER}_{\mathrm{BR}}$ & -0.011 & 0.082 & 0.103 & 0.087 & 0.063 & 0.117 & 0.103 & 0.070 & 0.095 & 0.083 & 0.160 & 0.075 \\
\hline Sample size & 73 & & 73 & & 73 & & 47 & & 47 & & 47 & \\
\hline$R_{\mathrm{m}}^{2}$ & 0.089 & & 0.117 & & 0.119 & & 0.556 & & 0.429 & & 0.400 & \\
\hline \multicolumn{13}{|c|}{ Without central air conditioning } \\
\hline Intercept & 0.625 & 0.523 & 7.422 & 0.674 & 4.974 & 0.726 & 12.963 & 27.266 & 4.952 & 2.133 & 4.117 & 4.549 \\
\hline$I_{\text {Enhanced }}$ & 0.353 & 0.142 & 0.450 & 0.190 & 0.452 & 0.208 & -0.193 & 1.207 & 0.411 & 0.259 & 0.011 & 0.432 \\
\hline$I_{\text {Control }}$ & 0.714 & 0.144 & 1.038 & 0.157 & 1.049 & 0.222 & 1.552 & 1.593 & 1.056 & 0.378 & 0.720 & 0.659 \\
\hline DETS & 0.348 & 0.138 & 0.894 & 0.152 & 0.465 & 0.171 & 1.030 & 1.059 & 0.694 & 0.519 & 0.925 & 0.627 \\
\hline $\log C_{\text {out }}$ & 0.345 & 0.177 & 0.301 & 0.291 & 0.312 & 0.226 & 0.040 & 1.364 & 0.122 & 0.475 & 0.995 & 0.987 \\
\hline $\mathrm{T}$ & 0.017 & 0.019 & 0.049 & 0.023 & -0.004 & 0.026 & -0.418 & 0.820 & 0.085 & 0.068 & -0.125 & 0.158 \\
\hline $\mathrm{RH}$ & 0.013 & 0.005 & 0.012 & 0.005 & 0.011 & 0.006 & -0.010 & 0.121 & 0.052 & 0.035 & 0.044 & 0.049 \\
\hline$A E R_{L R}$ & 0.092 & 0.105 & 0.046 & 0.124 & 0.058 & 0.155 & 0.806 & 2.234 & 0.015 & 0.492 & 0.184 & 0.867 \\
\hline $\mathrm{AER}_{\mathrm{BR}}$ & 0.034 & 0.054 & 0.056 & 0.069 & -0.041 & 0.063 & 0.225 & 0.341 & -0.010 & 0.069 & 0.036 & 0.189 \\
\hline Sample size & \multicolumn{2}{|c|}{167} & \multicolumn{2}{|c|}{167} & \multicolumn{2}{|c|}{167} & \multicolumn{2}{|c|}{91} & \multicolumn{2}{|c|}{91} & \multicolumn{2}{|c|}{91} \\
\hline$R_{\mathrm{m}}^{2}$ & \multicolumn{2}{|c|}{0.179} & \multicolumn{2}{|c|}{0.981} & \multicolumn{2}{|c|}{0.937} & \multicolumn{2}{|c|}{$\mathrm{NC}$} & \multicolumn{2}{|c|}{ NC } & \multicolumn{2}{|c|}{ NC } \\
\hline
\end{tabular}

Bolded values are significant at $\alpha=0.05$. NC denotes that an $R_{m}^{2}$ value could not be obtained.

$\mathrm{AER}=$ air exchange rates; $\mathrm{PM}=$ particulate matter; $\mathrm{PNC}=$ particle number count.

outcomes but statistically insignificant. (Models for the raw data, shown in Table $\mathrm{S} 9$, are similar but $\beta_{1}$ was significant for $0.3-1.0 \mu \mathrm{m}$ PNC.) In summer in homes with central air conditioning, $\beta_{1}$ was also positive for the three outcomes and significant for PM and $1-5 \mu \mathrm{m}$ PNC. Positive values indicate higher concentrations in the enhanced intervention as compared to the standard intervention; thus, the room ACs appeared to increase PM concentrations. However, other factors must be considered to interpret results. For example, the enhanced and standard interventions should have been equivalent in seasons other than summer. This is supported in the homes with central air conditioning where $\beta_{1}$ was not significant, but $\beta_{1}$ was positive and significant for the three outcomes in homes without central air conditioning, again indicating higher concentrations in the enhanced group. This trend also was shown in the unadjusted statistics presented earlier for both pre- and post-intervention cases (Tables 2 and 3).

Higher PM concentrations in the enhanced intervention group could have occurred for many reasons, for example, the presence of strong indoor emissions (like smoking), lower AERs associated with ACs, or greater air exchange between the bedroom and other spaces (possibly to distribute the cool air). While differences were not statistically significant, the standard intervention group had more homes with forced air systems than the enhanced group (94 vs. $82 \%$ ), and more homes with central air conditioning (38 vs. $22 \%$; Table S3). As mentioned, heating and cooling of these homes would remove some PM because of the furnace air filter. Also, while smoking rates and smoking rules in the two intervention groups did not differ statistically (Table S3), ETS tracers were detected more frequently in the enhanced group, specifically, in $23 \%$ of visits ( 26 of 115 visits) as compared to $11 \%$ of visits (15 of 137 visits) in the standard group. [ETS was detected in $24 \%$ of visits ( 23 of 94 visits) to the control group.] Unfortunately, the sample size does not permit further stratification or interactions that jointly address smoking, central and room air conditioning, season, and intervention group. Another possibility is a differential in the assignment of intervention groups. This was evaluated by re-estimating model 3 for only those households that passed the screening visit (representing $64 \%$ households). In summer for homes without central air conditioning, these models were similar to those just discussed except that $\beta_{1}$ was now statistically significant and positive, showing a detrimental effect of the room AC. The more important result is that during the balance of the year, while models using the data subset had very similar values of $\beta_{1}$, as seen earlier, this coefficient was not significant for any outcome in homes with or without central air conditioning. This change, the loss of significance, could represent bias in assigning the intervention group; however, since only 
the standard error of $\beta_{1}$ changed, it appears to be mostly an effect of sample size.

A second goal of model 3 was to determine whether a central AC altered the filter's effect, shown primarily by parameter $\beta_{2}$ (which multiples $I_{\text {Control, }, i}$, the variable denoting a control home). In nearly all cases, this coefficient was significant. In summer, we did not see consistent patterns in comparing $\beta_{2}$ for households with and without central ACs; for example, summer values of $\beta_{2}$ for PM and $0.3-1 \mu \mathrm{m}$ PNC were smaller for homes with air conditioning, but $\beta_{2}$ was larger or comparable using the raw data. Other seasons showed similar inconsistencies and differences among the three PM measures. Overall, these results do not show strong or consistent effects when a central AC was present. Like room ACs, central ACs can cause several effects. First, air circulated while cooling (and heating) can increase AERs in the space where the free-standing filter is installed, potentially lowering the reduction (in $\mu \mathrm{g} / \mathrm{m}^{3}$ ) that can be achieved using the filter. Second, air circulating through the heating/cooling system may also be filtered (depending on the type of 'furnace filter' installed), which will decrease PM levels throughout house. Third, homes with central air conditioning had lower AERs, especially in summer, which can either increase or decrease concentrations, depending on the relative strengths of indoor and outdoor sources. Because the statistical modeling used the logarithm of concentrations, the estimated parameters more closely represent the filter efficiency or percentage reduction in PM levels, which should have been unchanged even though the absolute reduction, for example, in terms of $\mu \mathrm{g} / \mathrm{m}^{3}$, may have been smaller in some homes with central air conditioning.

\section{Need for repeated measures}

The multiseason and repeated measures used in this study enabled an understanding of the long-term effectiveness of air filters for controlling air pollutants. Both indoor and outdoor PM concentrations, along with many of the factors governing pollutant levels, can vary by season. Consequently, representative and long-term concentration estimates can be obtained only using multiple measurements obtained in different seasons. Short-term variation in pollutant levels, for example, hour-to-hour and day-to-day variation, can also be large. Because we used mostly week-long averages, short-term variation is not expected to affect our conclusions. A second finding, not unique to this study but worth emphasizing, are the many determinants of PM concentrations. In addition to filter operation and season, PM concentrations in the present study were associated with ETS, number of children, outdoor pollutant levels, sweeping and dusting, outdoor $\mathrm{PM}_{2.5}$ concentration, central air conditioning, number of smokers, indoor/outdoor temperature and relative humidity, and AERs. In the intervention, the use of filters became the dominant factor affecting indoor concentrations; the largest influences in homes without filters are outdoor levels and smoking (Meng et al., 2009). The GEE models account for many factors potentially affecting filter performance, but they did not change the fundamental conclusions drawn in the unadjusted analyses. However, they tended to temper the effect size and to reduce variability.

The dynamic and widely varying patterns of filter use among the households are striking. Some households used the filter continuously, others not at all, and filter use tended to decline over time. These findings would not have been found without repeated measures.

\section{Strengths and limitations}

This study evaluated a large number of occupied homes in a susceptible population of primarily lowincome African Americans with an asthmatic child. Both integrated and continuous measurements over a week's time in multiple seasons were used to evaluate effects of air filters, ACs, seasonal variability, AERs, outdoor PM levels, and other factors that can influence indoor PM levels. The filter use measurements turned out to be instrumental as filter use in many of the households did not follow our expectations that this was a primarily passive intervention.

The study has several limitations. The numbers of homes in each group and season were not balanced, although home characteristics did not vary among groups. We emphasized weekly average data, and thus our analysis does not address short-term fluctuations. Limited information was available pertaining to PM emissions and determinants, for example, occupant activity, and window and door opening. While three types of PM measurements were utilized, the gravimetric measurements were not size-selective, although PM appeared to be dominated by small $(<1 \mu \mathrm{m}$ dia) particles based on correlations with $0.3-1.0 \mu \mathrm{m}$ PNCs, seasonal variations, and the literature. Indoor and outdoor emissions and concentrations were assumed to be independent of filter installation and operation; this could only be partly confirmed by the $\mathrm{CO}_{2}$ measurements or adjusted in the statistical models. Still, we have some concern that the filter's noise and drafts could either drive children away or possibly attract children (and maybe smokers). While we had continuous measurements regarding filter use, AC use was not monitored. The room AC units installed in the study homes did not provide forced ventilation. There may be biases due to the randomization into the three groups, although our examination did not show significant effects. Our sample size did not permit analyses that simultaneously accounted for interactions between season, filter use, air conditioning, and 


\section{Batterman et al.}

smoking. Finally, the results and statistical models may not apply to other cities or populations, although PM levels and the housing stock appear fairly typical of many residences in northern and eastern US cities.

\section{Conclusions}

Air quality parameters were monitored in 126 homes of asthmatic children in Detroit during 1-week periods in three or four seasons per year. Prior to the intervention, PM concentrations averaged $28 \pm 34 \mu \mathrm{g} / \mathrm{m}^{3}$. When present, ETS elevated PM levels in the child's bedroom by $12-14 \mu \mathrm{m} / \mathrm{m}^{3}$. PM levels were also associated with outdoor $\mathrm{PM}_{2.5}$ concentrations, temperature, wind speed, vacuuming, sweeping and dusting, number of pets, number of children, filter use, bedroom AER, heating system type, and presence of a central AC. In the intervention groups receiving a freestanding HEPA filter, PM concentrations averaged $14 \pm 10 \mu \mathrm{g} / \mathrm{m}^{3}$, representing approximately a $50 \%$ reduction in PM concentrations. Larger reductions were achieved with more continuous use of the filter. Filter effectiveness was not significantly different in homes with central ACs, and filter effectiveness did not change when a room AC was installed in the child's bedroom. Filter use, an important and revealing variable, varied greatly among households in the study and declined over the study period. Filter use was especially low during the long periods when IAQ was not being monitored. Thus, to sustain lasting reductions in PM exposures, strategies to ensure filter use should be an integral element of the intervention. Future analyses will clarify the impact of the filter and $\mathrm{AC}$ on asthma symptoms and respiratory health.

\section{Acknowledgements}

We thank the study participants, our staff including Sonya Grant-Pearson, Leonard Brakefield, Dennis Fair, Ricardo de Majo, Xiaodan Ren, Jie Zhou, Huda Elasaad and Andrew Ekstrom, and the CAAA Steering Committee members (Arab Community Center for Economic and Social Services (ACCESS); Community Health \& Social Services Center (CHASS); Detroit Hispanic Development Corporation (DHDC); Detro- iters Working for Environmental Justice (DWEJ); Friends of Parkside (FOP); Latino Family Services (LFS); Warren/Conner Development Coalition; City of Detroit Dept of Health and Wellness Promotion, and the University of Michigan Schools of Public Health and Medicine). This study was conducted as part of NIEHS grant R01-ESO14566-01A1, 'A Community Based Participatory Research Intervention for Childhood Asthma Using Air Filters and Air Conditioners'. Liuliu Du was supported in part by the China Scholarship Council (CSC).

\section{Supporting Information}

Additional Supporting Information may be found in the online version of this article:

Table S1 Temperatures and wind speed measured at Detroit City Airport during the sampling period (1 March 2009-31 October 2010).

Table S2 Outdoor concentrations of $\mathrm{PM}_{2.5}$ using spatial average over Detroit monitors.

Table S3 Characteristics of the study homes by randomization group.

Table S4 Filter use during week-long baseline and seasonal visits, and 'inter-seasonal' visit periods.

Table S5 Examples of variables associated with indoor pollutant levels; statistically significant associations are in bold and based on correlation (continuous variables, Spearman) or chi-square test (categorical variable).

Table S6 PM and $\mathrm{CO}_{2}$ concentrations stratified by presence of ETS tracer, season, and randomization group.

Table S7 GEE estimates for model 1 for PM, 0.3$1.0 \mu \mathrm{m}$ PNC, and $1-5 \mu \mathrm{m}$ PNC.

Table S8 GEE estimates for model 2 for PM, 0.3$1.0 \mu \mathrm{m}$ PNC, and $1-5 \mu \mathrm{m}$ PNC.

Table S9 GEE estimates for model 3 for PM, 0.3$1.0 \mu \mathrm{m} \mathrm{PNC}$, and $1-5 \mu \mathrm{m}$ PNC showing models stratified by summer 2010 and by central air conditioning.

Please note: Wiley-Blackwell are not responsible for the content or functionality of any supporting materials supplied by the authors. Any queries (other than missing material) should be directed to the corresponding author for the article.

\section{References}

Abt, E., Suh, H.H., Allen, G. and Koutrakis, P. (2000) Characterization of indoor particle sources: a study conducted in the metropolitan Boston area, Environ. Health Perspect., 108, 35-44.

Allen, R., Larson, T., Sheppard, L., Wallace, L. and Liu, L.J.S. (2003) Use of real-time light scattering data to estimate the contribution of infiltrated and indoor-gener- ated particles to indoor air, Environ. Sci. Technol., 37, 3484-3492.

Arlian, L.G., Neal, J.S., Morgan, M.S., Vyszenski-Moher, D.L., Rapp, C.M. and Alexander, A.K. (2001) Reducing relative humidity is a practical way to control dust mites and their allergens in homes in temperate climates, J. Allergy Clin. Immunol., 107, 99-104.
Batterman, S., Metts, T., Kalliokoski, P. and Barnett, E. (2002) Low-flow active and passive sampling of VOCs using thermal desorption tubes: theory and application at an offset printing facility, J. Environ. Monitor., 4, 361-370.

Batterman, S., Godwin, C. and Jia, C.R. (2005) Long duration tests of room air filters in cigarette smokers' 
homes, Environ. Sci. Technol., 39 7260-7268.

Batterman, S., Jia, C.R., Hatzivasilis, G. and Godwin, C. (2006) Simultaneous measurement of ventilation using tracer gas techniques and VOC concentrations in homes, garages and vehicles, J. Environ. Monitor., 8, 249-256.

Breen, M.S., Breen, M., Williams, R.W. and Schultz, B.D. (2010) Predicting residential air exchange rates from questionnaires and meteorology: model evaluation in central north Carolina, Environ. Sci. Technol., 44, 9349-9356.

Breysse, P.N., Buckley, T.J., Williams, D., Beck, C.M., Jo, S.J., Merriman, B., Kanchanaraksa, S., Swartz, L.J., Callahan, K.A., Butz, A.M., Rand, C.S., Diette, G.B., Krishnan, J.A., Moseley, A.M., Curtin-Brosnan, J., Durkin, N.B. and Eggleston, P.A. (2005) Indoor exposures to air pollutants and allergens in the homes of asthmatic children in inner-city Baltimore, Environ. Res., 98 , 167-176.

Center for Urban Studies., W.S.U. (2000) 2000 Census Demographic Profile of City of Detroit, Available online at http:// www.cus.wayne.edu/content/profiles/ 00SP1DetroitTracts.pdf, accessed on 15 Aug 2011.

Charles, S.M., Jia, C., Batterman, S.A. and Godwin, C. (2008) VOC and particulate emissions from commercial cigarettes: analysis of 2,5-DMF as an ETS tracer, Environ. Sci. Technol., 42, 1324-1331.

Crain, E.F., Walter, M., O'connor, G.T., Mitchell, H., Gruchalla, R.S., Kattan, M., Malindzak, G.S., Enright, P., Evans, R., Morgan, W. and Stout, J.W. (2002) Home and allergic characteristics of children with asthma in seven US urban communities and design of an environmental intervention: the Inner-City Asthma Study, Environ. Health Perspect., 110, 939-945.

Delfino, R.J., Zeiger, R.S., Seltzer, J.M., Street, D.H., Matteucci, R.M., Anderson, P.R. and Koutrakis, P. (1997) The effect of outdoor fungal spore concentrations on daily asthma severity, Environ. Health Perspect., 105, 622-635.

Du, L., Batterman, S., Parker, E.A., Godwin, C., Chin, J.-Y., O'toole, A., Robins, T.G., Brakefield-Caldwell, W. and Lewis, T. (2011) Particle concentrations and effectiveness of free-standing air filters in bedrooms of children with asthma in Detroit, Michigan, Build. Environ., 46, 2303-2313.

Eggleston, P.A., Butz, A., Rand, C., CurtinBrosnan, J., Kanchanaraksa, S., Swartz, L., Breysse, P., Buckley, T., Diette, G., Merriman, B. and Krishnan, J.A. (2005) Home environmental intervention in inner-city asthma: a randomized controlled clinical trial, Ann. Allergy Asthma Immunol., 95, 518-524.
Heroux, M.E., Clark, N., Van Ryswyk, K., Mallick, R., Gilbert, N.L., Harrison, I., Rispler, K., Wang, D., Anastassopoulos, A., Guay, M., Macneill, M. and Wheeler, A.J. (2010) Predictors of indoor air concentrations in smoking and non-smoking residences, Int. J. Environ. Res. Public Health, 7, 3080-3099.

Hussein, T., Korhonen, H., Herrmann, E., Hameri, K.H., Lehtinen, K.E.J. and Kulmala, M. (2005) Emission rates due to indoor activities: indoor aerosol model development, evaluation, and applications, Aerosol Sci. Technol., 39, 11111127.

Jia, C., Batterman, S. and Godwin, C. (2007) Continuous, intermittent and passive sampling of airborne VOCs, J. Environ. Monitor., 9, 1220-1230.

Keeler, G.J., Dvonch, J.T., Yip, F.Y., Parker, E.A., Israel, B.A., Marsik, F.J., Morishita, M., Barres, J.A., Robins, T.G., Brakefield-Caldwell, W. and Sam, M. (2002) Assessment of personal and community-level exposures to particulate matter among children with asthma in Detroit, Michigan, as part of Community Action Against Asthma (CAAA), Environ. Health Perspect., 110, 173-181.

Klepeis, N.E., Nelson, W.C., Ott, W.R., Robinson, J.P., Tsang, A.M., Switzer, P., Behar, J.V., Hern, S.C. and Engelmann, W.H. (2001) The National Human Activity Pattern Survey (NHAPS): a resource for assessing exposure to environmental pollutants, J. Expo. Anal. Environ. Epidemiol., 11, 231-252.

Lai, H.K., Bayer-Oglesby, L., Colvile, R., Gotschi, T., Jantunen, M.J., Kunzli, N., Kulinskaya, E., Schweizer, C. and Nieuwenhuijsen, M.J. (2006) Determinants of indoor air concentrations of $\mathrm{PM}_{2.5}$, black smoke and $\mathrm{NO}_{2}$ in six European cities (EXPOLIS study), Atmos. Environ., 40, 1299-1313.

LeBouf, R., Yesse, L. and Rossner, A. (2008) Seasonal and diurnal variability in airborne mold from an indoor residential environment in northern New York, J. Air Waste Manag. Assoc., 58, 684-692.

Lewis, T.C., Robins, T.G., Joseph, C.L.M., Parker, E.A., Israel, B.A., Rowe, Z., Edgren, K.K., Salinas, M.A., Martinez, M.E. and Brown, R.W. (2004) Identification of gaps in the diagnosis and treatment of childhood asthma using a community-based participatory research approach, J. Urban Health, 81, 472-488.

Lintner, T.J. and Brame, K.A. (1993) The effects of season, climate, and air-conditioning on the prevalence of Dermatophagoides mite allergens in household dust, J. Allergy Clin. Immunol., 91, 862867.

Macintosh, D.L., Myatt, T.A., Ludwig, J.F., Baker, B.J., Suh, H.H. and Spengler, J.D. (2008) Whole house particle removal and clean air delivery rates for in-duct and portable ventilation systems, J. Air Waste Manag. Assoc., 58, 1474-1482.

McCormack, M.C., Breysse, P.N., Hansel, N.N., Matsui, E.C., Tonorezos, E.S., Curtin-Brosnan, J., Williams, D.L., Buckley, T.J., Eggleston, P.A. and Diette, G.B. (2008) Common household activities are associated with elevated particulate matter concentrations in bedrooms of inner-city Baltimore pre-school children, Environ. Res., 106, 148-155.

McCormack, M.C., Breysse, P.N., Matsui, E.C., Hansel, N.N., Williams, D., CurtinBrosnan, J., Eggleston, P., Diette, G.B. and Ctr Childhood Asthma Urban, E. (2009) In-home particle concentrations and childhood asthma morbidity, Environ. Health Perspect., 117, 294-298.

Meng, Q.Y., Spector, D., Colome, S. and Turpin, B. (2009) Determinants of indoor and personal exposure to $\mathrm{PM}_{2.5}$ of indoor and outdoor origin during the RIOPA study, Atmos. Environ., 43, 5750-5758.

Morey, P.R., Crawfird, G.B. and Rottersman, R.B. (2011) Indoor air quality in nonindustrial occupational environments. In: Rose, V.E. and Chohrssen, B. (eds) Patty's Industrial Hygiene, 6th edn, New York, John Wiley \& Sons, Inc, 23772468.

Munir, A.K.M., Bjorksten, B., Einarsson, R., Schou, C., Ekstrandtobin, A., Warner, A. and Kjellman, N.I.M. (1994) Cat (Fel d I), Dog (Can f I), and cockroach allergens in homes of asthmatic children from 3 climatic zones in Sweden, Allergy, 49, 508-516.

Nazaroff, W.W., Hung, W.Y., Sasse, A. and Gadgil, A.J. (1993) Predicting regional lung deposition of environmental tobacco-smoke particles, Aerosol Sci. Technol., 19, 243-254.

Rodes, C.E., Lawless, P.A., Thornburg, J.W., Williams, R.W. and Croghan, C.W. (2010) DEARS particulate matter relationships for personal, indoor, outdoor, and central site settings for a general population, Atmos. Environ., 44, 13861399.

Scapellato, M.L., Canova, C., De Simone, A., Carrieri, M., Maestrelli, P., Simonato, L. and Bartolucci, G.B. (2009) Personal $\mathrm{PM}_{10}$ exposure in asthmatic adults in Padova, Italy: seasonal variability and factors affecting individual concentrations of particulate matter, Int. J. Hyg. Environ. Health, 212, 626-636.

Sublett, J.L., Seltzer, J., Burkhead, R., Williams, P.B., Wedner, H.J. and Phipatanakul, W. (2010) Air filters and air cleaners: rostrum by the American Academy of Allergy, Asthma \& Immunology Indoor Allergen Committee, J. Allergy Clin. Immunol., 125, 32-38.

Thornburg, T., Rodes, C.E., Lawless, P.A. and Williams, R. (2009) Spatial and temporal variability of outdoor coarse particulate matter mass concentrations 


\section{Batterman et al.}

measured with a new coarse particle sampler during the Detroit Exposure and Aerosol Research Study, Atmos. Environ., 43, 4251-4258.

Vanderheide, S., Kauffman, H.F., Dubois, A.E.J. and Demonchy, J.G.R. (1997) Allergen reduction measures in houses of allergic asthmatic patients: effects of air-cleaners and allergen-impermeable mattress covers, Eur. Respir. J., 10, 1217-1223.

Wallace, L. (1996) Indoor particles: a review, J. Air Waste Manag. Assoc., 46, 98-126.

Weisel, C.P., Zhang, J., Turpin, B.J., Morandi, M.T., Colome, S., Stock, T.H. and Spektor, D.M. (2005) Relationships of Indoor, Outdoor, and Personal Air (RIOPA) Part I. Collection Methods and Descriptive Analyses, Available online at http://www.sph.uth.tmc.edu/mleland/

Pages/Press\% 20Releases/RIOPA \% 20

Part \%20I\%20Whole\%20Book\%20

Web\%20secure.pdf, accessed on 30 July 2011.

Williams, R., Rea, A., Vette, A., Croghan, C., Whitaker, D., Stevens, C., Mcdow, S., Fortmann, R., Sheldon, L., Wilson, H., Thornburg, J., Phillips, M., Lawless, P., Rodes, C. and Daughtrey, H. (2009) The design and field implementation of the
Detroit Exposure and Aerosol Research Study, J. Expo. Sci. Environ. Epidemiol., 19, 643-659.

Xu, Y., Raja, S., Ferro, A.R., Jaques, P.A., Hopke, P.K., Gressani, C. and Wetzel, L.E. (2010) Effectiveness of heating, ventilation and air conditioning system with HEPA filter unit on indoor air quality and asthmatic children's health, Build. Environ., 45, 330-337.

Zheng, B. (2000) Summarizing the goodness of fit on generalized linear models for longitudinal data, Stat. Med., 19, 12651275. 